\title{
A POLIANILINA NO CENÁRIO AMBIENTAL: UMA ABORGAGEM SOBRE FOTOCATÁLISE HETEROGÊNEA
}

\author{
Vanessa M. M. Vargasª, Carla Dalmolina, Sérgio H. Pezzina, Marcela Mohallem Oliveira ${ }^{\mathrm{b}}$ e Patricio Peralta-Zamorac,* \\ ${ }^{a}$ Centro de Cências Tecnológicas, Universidade do Estado de Santa Catarina, 89219-710 Joinville - SC, Brasil \\ bDepartamento Acadêmico de Química e Biologia, Universidade Tecnológica Federal do Paraná, 80230-901 Curitiba - PR, Brasil \\ 'Departamento de Química, Universidade Federal do Paraná, 81531-990 Curitiba - PR, Brasil
}

Recebido em 27/07/2017; aceito em 08/11/2017; publicado na web em 18/12/2017

\begin{abstract}
POLYANILINE IN THE ENVIRONMENTAL SCENARIO: AN APPROACH ON HETEROGENEOUS PHOTOCATALYSIS. Polyaniline is a conducting polymer that has recently been studied regarding its potential in the removal of contaminants by heterogeneous photocatalysis. Since it is a polymer with a high absorption capacity of photons in the visible region, it promotes the photosensitization of catalysts that are typically inactive in solar systems. The increasing number of publications applying photocatalysis and composite catalysts based on polyaniline highlights the importance of this subject. This review systematizes the most important and specific contributions of composite catalysts formed by polyaniline. The main mechanisms proposed for photosensitization, which show the synergism between the phases of the composite, are summarized. Moreover, the relevance of morphology and conductivity of the composite catalyst, operating parameters (eg. pH, and light source contaminant) are some of the aspects discussed, revealing how these differ from traditional catalysts. Future prospects for the continuation and improvement of this issue mainly involve a greater variety of contaminant removal tests and understanding of relations between the structure of the material and its photocatalytic property.
\end{abstract}

Keywords: conducting polymer; photocatalytic; solar energy; photosensitization.

\section{INTRODUÇÃO}

Nos últimos 20 anos, inúmeros trabalhos demonstraram a elevada eficiência de degradação da fotocatálise heterogênea, frente a inúmeras espécies químicas consideradas poluentes prioritários ou emergentes. A fotocatálise heterogênea é viabilizada pela geração de pares elétron/buraco $\left(\mathrm{e}^{-/} / \mathrm{h}^{+}\right)$, gerados quando um semicondutor é irradiado com fótons de energia maior ou igual ao seu band gap. Embora elétrons e buracos sejam bastante reativos, admite-se que a principal rota de degradação é mediada por radical hidroxila $(\mathrm{OH})$ que surge da reação da lacuna com íon hidroxila o moléculas de água previamente adsorvidas na superfície do semicondutor. ${ }^{1-4}$ Infelizmente, grande parte dos fotocatalisadores correspondem a óxidos semicondutores que apresentam band gap de energia correspondente aos comprimentos de onda da região ultravioleta do espectro, $\operatorname{como~} \mathrm{TiO}_{2}(\lambda \approx 388 \mathrm{~nm})$ e $\mathrm{ZnO}(\lambda \approx 370 \mathrm{~nm})$, o que faz com que a sua eficiência catalítica em sistemas assistidos por radiação solar seja muito baixa. ${ }^{5-9}$

Desta forma, a procura de sistemas catalíticos assistidos por energia solar tem sido alvo constante de pesquisas, objetivando, não apenas a redução de custos, mas também a implementação de sistemas operando em grande escala. Dentre as principais alternativas utilizadas para ampliar a foto-resposta de catalisadores pouco ativos sob luz visível destacam-se o desenvolvimento de catalisadores dopados por metais e não-metais, de catalisadores associados a outros semicondutores e o uso de processos sensibilizados por corantes. ${ }^{8-10}$

Recentemente, uma nova estratégia em síntese de catalisadores compósitos surgiu como resposta à necessidade de potencialisar a fotocatálise de contaminantes sob luz visível ou solar, que consiste na associação de catalisadores inorgânicos, usualmente óxidos semicondutores, e polímeros condutores (PC) coloridos. Dentre os principais polímeros condutores a polianilina merece destaque, em virtude do seu baixo custo, da sua facilidade de síntese, do seu caráter atóxico, da sua elevada estabilidade térmica e à exposição à luz, da

*e-mail: zamora@ufpr.br sua ampla absorção de luz visível e infravermelho próximo e da alta mobilidade e separação de cargas. ${ }^{7,11-15}$

Vários trabalhos ressaltam a ocorrência de um efeito sinérgico entre polianilina e catalisadores inorgânicos, o que resulta em sistemas fotocatalíticos promissores para a remoção de contaminantes. . $^{6,12,13,15-22}$

\section{Polianilina}

A partir da década de 70, com a descoberta das formas dopadas de polímeros capazes de conduzir corrente elétrica, uma vasta área de pesquisa e de aplicações destes materiais foi estabelecida. A polianilina (PANI), dentre os polímeros condutores (PC), tem recebido destaque devido a sua boa estabilidade, fácil obtenção e amplo leque de aplicações. Os principais estudos e aplicações da polianilina se relacionam com sensores/biosensores, transistores, eletrodos em baterias, supercapacitores, coberturas anticorrosivas, dispositivos fotovoltaicos e eletrocrômicos, fotocatalisadores, entre outras..$^{7,17,23,24}$ O uso da polianilina em aplicações ambientais envolve células solares sensibilizadas, ${ }^{17,25,26}$ produção de hidrogênio, ${ }^{27,28}$ e fotocatálise heterogênea para remoção de contaminantes e desinfecção..$^{21,29-31}$

$\mathrm{Na}$ última década houve crescente aumento das publicações abordando processos fotocatalíticos e polianilina, além de outros polímeros condutores (Figura 1). Embora esse levantamento da literatura não considere exatamente todas as publicações, os dados obtidos evidenciam uma tendência geral do crescente interesse da comunidade científica quanto ao uso de polímeros condutores (especialmente a polianilina) em processos fotocatalíticos. Contudo, menos de $1 \%$ ao ano das publicações em fotocatálise incluem o uso da polianilina ou outros polímeros condutores, o que justifica a importância de desenvolver mais pesquisas com este tema.

Dentre os primeiros estudos publicados, que contemplaram o uso da polianilina como modificador, se destaca o trabalho realizado por Liu, Guo e Jin ${ }^{32}$ em 1991, que demostrou a elevada capacidade de degradação do catalisador compósito formado por $\mathrm{TiO}_{2}$ e polianilina na 
degradação de fenol por processos assistidos por radiação solar. Outro estudo pioneiro no cenário em avaliação foi publicado por um grupo brasileiro em 1996 (Zamora et al.), ${ }^{33}$ o qual mostrou o desempenho da polianilina na degradação de efluente têxtil, ficando evidente a direção para uso de materiais compósitos. A partir de então, conforme a Figura 1, apenas após 2011 houve aumento significativo de publicações nesse tema. Pei e Luan ${ }^{34}$ em 2012 e Tahir e Amin ${ }^{35}$ em 2013 fizeram citações indicando polímeros condutores como uma nova e promissora linha de fotossensibilizadores. É importante destacar que recentemente (2015), Reddy, Hassan e Gomes, ${ }^{31}$ Riaz, Ashraf e Kashyap ${ }^{29}$ e Ansari et al. ${ }^{36}$ publicaram os primeiros artigos de revisão sobre catalisadores fotossensibilizados por polímeros condutores, considerando $\mathrm{TiO}_{2} \mathrm{e} \mathrm{PC}$, catalisadores inorgânicos e PC, e catalisadores inorgânicos e politiofeno, respectivamente. A divulgação desses trabalhos representa, de certo modo, a consolidação de polímeros condutores como uma nova classe de fotossensibilizadores. Entretanto, ainda há um campo fértil de pesquisa a ser explorado quanto à síntese, condições de fotocatálise, mecanismos de fotossensibilização, entre outros aspectos envolvendo novos catalisadores compósitos baseados em polianilina.

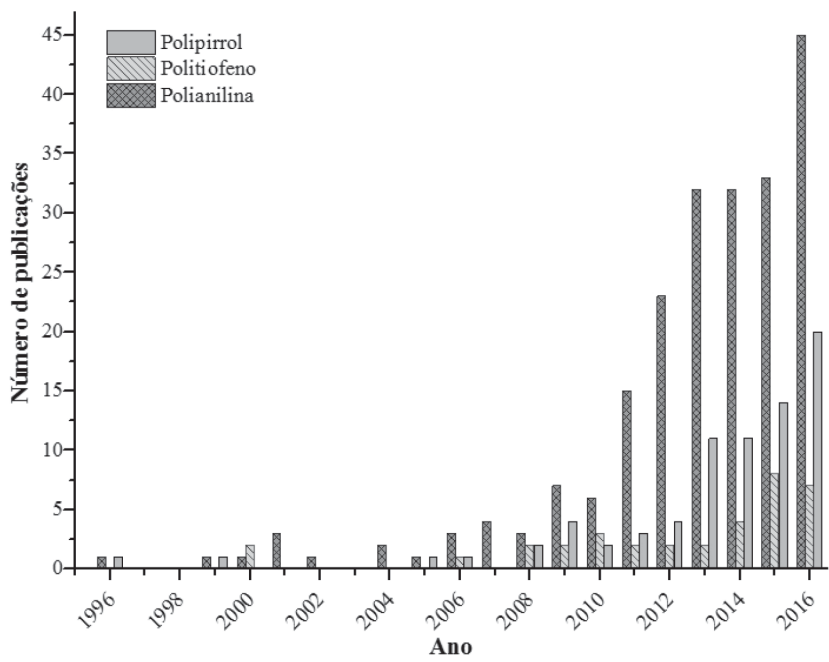

Figura 1. Números anuais de publicações envolvendo fotocatálise heterogênea e polianilina, polipirrol e politiofeno. (fonte: http://www.scopus.com, termos de pesquisa para cada polímero: "Photocatalytic and Polyaniline")

A polianilina, obtida a partir da polimerização da anilina, é formada por unidades de repetição que contém uma forma reduzida (dois anéis benzenóides) e outra oxidada (um anel quinóide e um benzenóide) (Figura 2), sendo que a forma chamada de esmeraldina $(y=0,5)$, quando dopada por protonação, é a que pode apresentar os maiores valores de condutividade elétrica.
A Figura 2 mostra que a dopagem da PANI ocorre em meio ácido, através da protonação do átomo de nitrogênio dos sítios básicos (aminas e iminas), situação na qual há despopulação parcial do sistema de elétrons $\pi$ (oxidação parcial), caracterizando dopagem do tipo $p$. A partir dessa etapa haverá a formação de estados eletrônicos localizados no gap, conhecidos como estados polarônicos, resultado das distorções da cadeia polimérica em torno das cargas geradas na protonação. Devido à carga positiva gerada no processo de dopagem, a eletroneutralidade da cadeia polimérica é garantida pela ação de ânions, chamados dopantes, normalmente vindos do próprio ácido utilizado para a protonação. A condutividade da PANI está diretamente relacionada com o tipo de ânion e o grau de dopagem, extensão da conjugação do sistema $\pi$ e conformação das cadeias poliméricas. Quando a polianilina é submetida ao processo de dopagem com ácidos que contenham ânions volumosos e solventes que interajam com estes ânions, as cadeias poliméricas passam a assumir uma conformação estendida, o que facilita o processo de transporte de cargas, aumentando a condutividade. Nas cadeias com conformação estendida existe maior interação entre os estados polarônicos, promovendo deslocalização e maior extensão da conjugação $\pi$ e, consequentemente, aumento da condutividade. Outro fator importante relacionado ao aumento da condutividade da PANI está associado com a total protonação dos grupos iminas, por isso, o grau de dopagem deste polímero depende do $\mathrm{pH}$ da solução ácida em que está inserido (Figura 2B). ${ }^{37-42}$

O desempenho da polianilina em doar elétrons, receber e transportar buracos sob incidência de fotóns com energia na região visível do espectro sugere um grande potencial para sua aplicação em fotocatálise heterogênea. ${ }^{13,15,43}$

\section{A polianilina como fotossensibilizador em fotocatálise heterogênea}

As propriedades ópticas da polianilina são responsáveis pelo seu potencial em atuar como fotossensibilizador de óxidos metálicos semicondutores como o $\mathrm{TiO}_{2}, \mathrm{ZnO}$, entre outros, que são normalmente inativos à luz visível. As transições eletrônicas da PANI dopada de coloração verde (sal esmeraldina) são bem conhecidas e marcadas pela presença de estados polarônicos no gap. O espectro UV-Vis do sal esmeraldina apresenta três bandas características: duas bandas em aproximadamente $\sim 320$ - $380 \mathrm{~nm} \mathrm{e} \sim 415-450 \mathrm{~nm}$ referentes as transições $\pi-\pi^{*}$ e pôlaron $-\pi^{*}$, respectivamente, e uma terceira banda larga situada na faixa do visível entre $\sim 700$ à $850 \mathrm{~nm}$ indicando a transição $\pi$-pôlaron..$^{15,40,41,44-46}$ Portanto, num catalisador compósito, o sinergismo entre a polianilina e o óxido metálico potencializa a oxidação de contaminantes sob radiação solar, aproveitando grande parte da energia incidente que corresponde à faixa do visível.

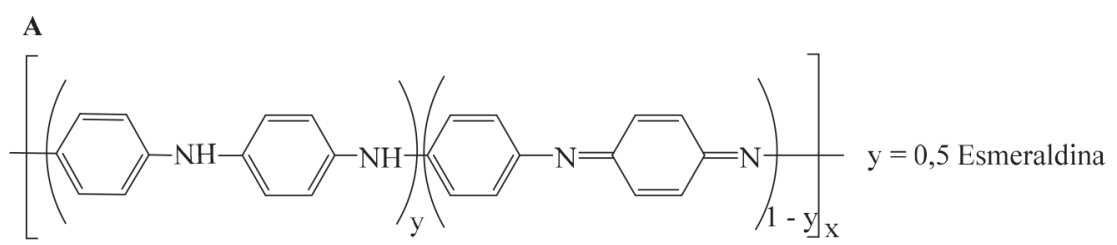

*

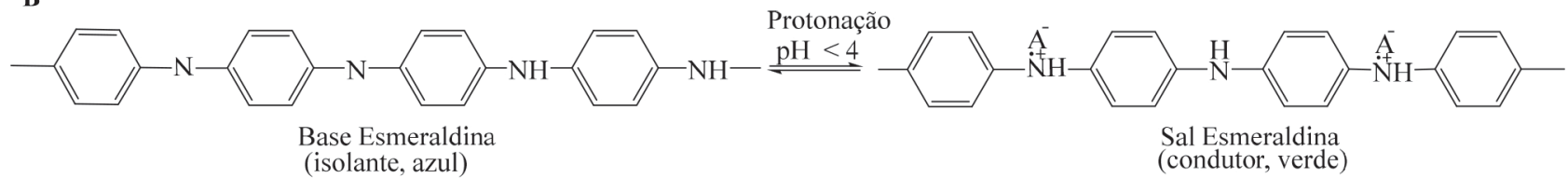

Figura 2. (A) Unidade de repetição da polianilina na forma conhecida como esmeraldina. (B) reação de dopagem via protonação da forma básica (base esmeraldina) para o sal esmeraldina 

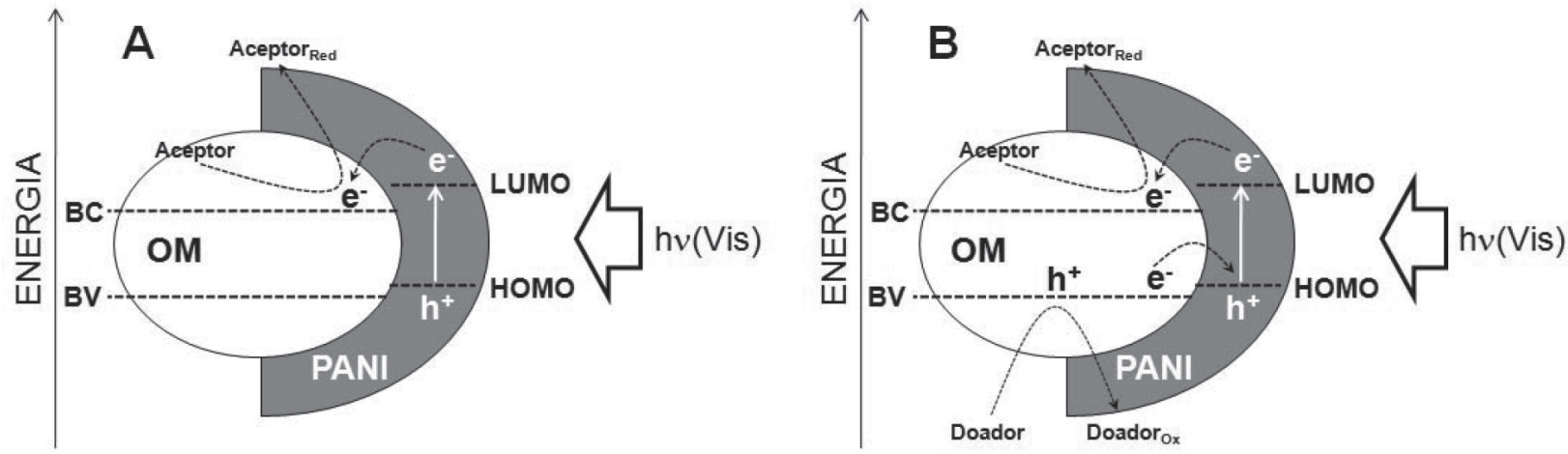

Figura 3. Representação esquemática das principais vias mecanísticas de fotossensibilização de catalisadores compósitos baseados em polianilina sob luz visível. (A) Mecanismo fundamentado na transferência de elétrons excitados em LUMO da PANI para a BC do óxido metálico (OM), (B) Mecanismo complementar em que elétrons da BV do OM são transferidos para o buraco gerado em HOMO na PANI, resultando num buraco em BV do óxido com potencial oxidante

A propriedade de condução elétrica da polianilina também é fundamental no mecanismo de fotossensibilização. Polianilina na sua forma dopada (sal esmeraldina) pode apresentar valores de condutividade comparáveis aos encontrados em semicondutores, na ordem de $0.1-10 \mathrm{~S} \mathrm{~cm}^{-1} \cdot \cdot^{19,23,40,44,47-50} \mathrm{Em}$ função das condições experimentais de síntese e dopagem, a polianilina pode apresentar comportamento metálico de condução, sendo que valores acima de $200 \mathrm{~S} \mathrm{~cm}^{-1}$ e chegando na ordem de $10^{3} \mathrm{~S} \mathrm{~cm}^{-1}$ já foram obtidos. ${ }^{37,40,51}$ A influência dessa propriedade na fotocatálise está associada às junções n-p formadas entre óxidos metálicos e polianilina, descritos como semicondutores tipo n e p, respectivamente..$^{13,29,52}$ A partir dessas junções, quando a polianilina recebe fótons que promovam seus elétrons à estados de energia mais elevados, o óxido pode recebê-los em sua banda de condução, em seguida, a polianilina passa a transportar carga positiva (buraco: $\mathrm{h}^{+}$) e o óxido, negativa (elétrons: $\left.\mathrm{e}^{-}\right) .^{53,54}$ Assim, o aumento da eficiência pelo uso de catalisadores compósitos está relacionado com as propriedades de transporte de carga, maior separação de cargas e redução da recombinação elétron/buraco. . $^{13,29,55}$

Associando as informações anteriores, o mecanismo de fotossensibilização pode ser compreendido pela disposição dos níveis de energia LUMO (lowest unoccupied molecular orbital) da polianilina (PANI) e da banda de condução (BC) do óxido metálico (OM). Ao incidir fótons de energia correspondente à faixa visível do espectro $\left(h v_{\text {(vis })}\right)$, elétrons dos orbitais HOMO do polímero são promovidos para os orbitais LUMO, que são transferidos para a BC do óxido metálico. Esses elétrons são transferidos para superfície do catalisador e participam de reações com $\mathrm{O}_{2}$ (aceptor de elétrons) que levam a formação de radicais $\mathrm{O}_{2}{ }^{-}$(Eq. 2) e ${ }^{\circ} \mathrm{OH}$ (Eq. 3) capazes de oxidar moléculas de contaminantes (Figura 3A) ${ }^{6,7,12,13,15-22,54-58}$ Esta via de fotossensibilização é a mais amplamente divulgada na literatura, e as equações 1 a 3 sumarizam as reações marcantes desta via mecanística.

$$
\begin{aligned}
& \mathrm{PANI} / \mathrm{OM}+h \mathrm{v}_{\text {(vis) }} \rightarrow \text { PANI }\left(\mathrm{h}^{+}{ }_{\text {Hомо }}\right) / \mathrm{OM}\left(\mathrm{e}^{-}{ }_{\mathrm{BC}}\right) \\
& \text { PANI / OM (e } \left.\text { e }^{-}{ }^{-}\right)+\mathrm{O}_{2} \rightarrow \mathrm{O}_{2}{ }^{-} \\
& \mathrm{PANI} / \mathrm{OM}\left(\mathrm{e}^{-}{ }_{\mathrm{BC}}\right)+\mathrm{O}_{2}^{-}+2 \mathrm{H}^{+} \rightarrow \cdot \mathrm{OH}+{ }^{-} \mathrm{OH}
\end{aligned}
$$

Uma descrição complementar do mecanismo propõe que ocorre a transferência do elétron da banda de valência (BV) do óxido para o buraco gerado em HOMO (highest occupied molecular orbital) na polianilina. Esse evento resulta num buraco na BV do óxido com potencial oxidante capaz de reagir com as moléculas do contaminante ou ainda com a água, formando ${ }^{\circ} \mathrm{OH}$ (Figura 3B e Equações 4 - 6).$^{7,52,59}$ Nesse mecanismo, fica evidente que há um sistema cíclico de elétrons, que é sustentado pelas reações entre as substâncias do meio e transferências eletrônicas entre as fases do compósito. Pei e Luan $^{34}$ descrevem a importância da regeneração do fotossensibilizador quanto à falta de elétrons, para que se sustente o ciclo de fotoreações; o que corrobora para a validação dessa via mecanística.

PANI $\left(\mathrm{h}^{+}{ }_{\text {HOMO }}\right) / \mathrm{OM}\left(\mathrm{e}^{-}{ }_{\text {BV }}\right) \underset{h v(\text { vis })}{\longrightarrow}$ PANI $\left(\mathrm{e}^{-}{ }_{\text {HOMO }}\right) / \mathrm{OM}\left(\mathrm{h}^{+}{ }_{\mathrm{BV}}\right)$

$\mathrm{PANI} / \mathrm{OM}\left(\mathrm{h}^{+}{ }_{\mathrm{BV}}\right)+\mathrm{H}_{2} \mathrm{O} \rightarrow \cdot \mathrm{OH}+\mathrm{H}^{+}$

$\mathrm{PANI} / \mathrm{OM}\left(\mathrm{h}_{\mathrm{BV}}^{+}\right)+\mathrm{R} \rightarrow \mathrm{R}_{\text {produtos de degradação }}$

Outra sugestão de mecanismo considera a incidência apenas de radiação UV. Nessa situação, elétrons do óxido metálico $(\mathrm{OM})$ e da polianilina são promovidos aos seus estados de energia mais altos, resultando numa maior densidade de elétrons na banda de condução tanto do óxido quanto no LUMO do polímero, além de buracos na banda de valência e no HOMO. Em função da disposição dos níveis de energia, a separação de cargas é favorecida, devido às transferências de elétrons do LUMO da PANI para a BC do óxido metálico, e buracos da BV para o HOMO (Figura 4). A formação de radicais hidroxila e a degradação do contaminante $(\mathrm{R})$ ocorrem através de reações nos sítios redutores e oxidantes do óxido metálico (Equações 7 - 9). ${ }^{13,43,60,61}$

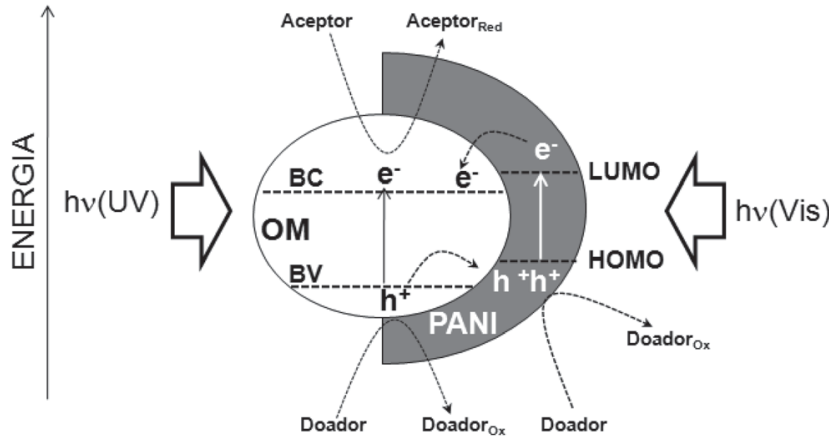

Figura 4. Representação esquemática da via mecanística de fotossensibilização de catalisadores compósitos baseados em polianilina sob luz UV ou visível incluindo a excitação do OM por radiação UV. A formação de radicais hidroxila e a degradação do contaminante ocorrem através de reações nos sítios redutores e oxidantes do material (Equações 7 - 9)

$\mathrm{PANI} / \mathrm{OM}+h \mathrm{v}_{(\mathrm{UV})} \rightarrow \mathrm{PANI}\left(\mathrm{h}^{+} / \mathrm{e}^{-}\right) / \mathrm{OM}\left(\mathrm{h}^{+} / \mathrm{e}^{-}\right)$

$\mathrm{e}^{-}{ }_{\mathrm{BC}}+\mathrm{O}_{2} \rightarrow \mathrm{O}_{2}^{--} \stackrel{2 \mathrm{H}^{+}}{\longrightarrow} \mathrm{OH}+{ }^{-} \mathrm{OH}$

$\mathrm{h}^{+}{ }_{\mathrm{BV}}+\mathrm{H}_{2} \mathrm{O} / \mathrm{R} \rightarrow \cdot \mathrm{OH}+\mathrm{H}^{+} / \mathrm{R}_{\text {produtos de degradacăo }}$

Em alguns casos, o catalisador inorgânico já possui band gap de energia correspondente aos comprimentos de onda da região visível do espectro (exemplos: $\mathrm{CdS}$ e $\mathrm{Bi}_{2} \mathrm{WO}_{6}$ ) e, portanto, quando associados a polianilina, ambos absorvem fótons que promovem seus elétrons para níveis mais altos de energia. Por isso, assim como descrito para 
sistemas que operam com UV, há alta densidade de elétrons e buracos tanto na polianilina quanto no catalisador inorgânico. As transferências dessas cargas e a formação de sítios oxidantes e redutores também ocorrem de forma similar àquela para UV (Figura 4)..$^{62-66}$

Em sistemas solares quando uma parcela de radiação UV está presente, ou ainda, com o uso de radiação artificial sem filtros, haverá contribuição de ambos os mecanismos propostos para luz visível e ultravioleta. ${ }^{13}$ Os estudos que envolvem apenas luz UV ou visível são importantes justamente porque em sistemas solares ambas estão presentes, e por isso é preciso compreender como os catalisadores formados por PANI respondem a cada uma delas.

Finalmente, é importante salientar que alguns autores sugerem que os buracos formados na polianilina, seja sob radiação visível ou UV, são capazes de oxidar moléculas do contaminante (R) e também de reagirem com água para produzir ${ }^{\circ} \mathrm{OH}$ (Equação $10 \mathrm{e}$ Figura 4). ${ }^{13,19,60,63,67,68}$

$\mathrm{OM} / \mathrm{PANI}\left(\mathrm{h}^{+}{ }_{\text {HOMO }}\right)+\mathrm{H}_{2} \mathrm{O} / \mathrm{R} \rightarrow{ }^{\circ} \mathrm{OH}+\mathrm{H}^{+} / \mathrm{R}_{\text {produtos de degradação }}$

Diante dessas propostas de mecanismos encontradas na literatura, a potencialidade desses materiais compósitos pode ser analisada sob dois aspectos: o primeiro trata efetivamente sobre a fotossensibilização à luz visível, que viabiliza o uso de energia solar. Já um segundo aspecto se refere à melhora na separação das cargas geradas (elétron/ buraco), à redução da taxa de recombinação, e à maior disponibilidade de sítios onde há formação de espécies oxidantes como ${ }^{\circ} \mathrm{OH}$, o que ocorre sob luz visível ou ultravioleta. ${ }^{13}$ Por isso, são encontrados trabalhos em que somente a radiação ultravioleta é aplicada em sistemas com compósitos baseados em polianilina. . $^{611,12,22,43,60,61,69-71}$ Em diversos casos, o catalisador sensibilizado com PANI demonstra maior eficiência fotocatalítica, sob luz UV, quando comparado aos catalisadores convencionais de óxidos metálicos isolados. ${ }^{6,11,22,54,56,61,70-74}$ Esse cenário mostra a abrangência e o potencial da polianilina frente aos sistemas convencionais e já consolidados em fotocatálise que envolvem a luz UV.

A forma como o fotossensibilizador (polianilina) interage com o catalisador inorgânico, seja por ligação covalente ou interação eletrostática, exerce grande influência nas transferências eletrônicas e eficiência fotocatalítica. ${ }^{34}$ Portanto, o estudo da interface do material compósito é fundamental na compreensão dos efeitos sinérgicos das junções n-p e na consolidação das propostas de mecanismos descritas até aqui. Diante disso, algumas técnicas de caracterização de materiais, especialmente as espectroscópicas e fotoeletroquímicas, trazem informações importantes sobre as transferências de carga na interface do compósito. ${ }^{43,54,75}$ As espectroscopias de fotoluminescência (EL) e de impedância eletroquímica (EIE) têm sido aplicadas para evidenciar a separação e mobilidade de cargas (elétron/buraco) entre as fases do compósito. Diversos estudos de EL e EIE têm demonstrado que a presença da polianilina é fundamental na separação e transferência de cargas, o que se traduz em melhor atividade fotocatalítica para o catalisador compósito em relação ao catalisador isolado. . $14,15,43,52,54,55,61,75-78^{-1}$

A determinação da fotocorrente gerada pelo catalisador e a conversão de fóton incidente em corrente (IPCE) também estão relacionadas diretamente com a maior eficiência fotocatalítica de catalisadores compósitos..$^{9,52,54,66,76,78,79}$ Deng et al. ${ }^{78}$ mostraram que catalisador $\mathrm{PANI}_{\text {TiO }}$-microesfera foi capaz de gerar cerca de $0,11 \mu \mathrm{A} \mathrm{cm}^{-2}$ em fotocorrente e remoção de corantes acima de $95 \%$ sob luz visível, enquanto que, apenas $\mathrm{TiO}_{2}$-microesfera em torno de $0,03 \mu \mathrm{A} \mathrm{cm}{ }^{-2}$ e 60 a $70 \%$ de remoção de corantes. No estudo feito por Li et al. ${ }^{52}$ com $\mathrm{PANI}^{\mathrm{TiO}}{ }_{2}$-nanotubos na remoção de rodamina b sob luz visível, dentre todos os materiais sintetizados, aquele com maior geração de fotocorrente $\left(6 \mu \mathrm{A} \mathrm{cm}{ }^{-2}\right)$ promoveu maior remoção do corante, cerca de $90 \%$. Além disso, nesse estudo, o uso de apenas nanotubos de $\mathrm{TiO}_{2}$ apresentou um desempenho inferior aos demais catalisadores testados, com fotocorrente $1,4 \mu \mathrm{A} \mathrm{cm} \mathrm{cm}^{-2}$ e cerca de $35 \%$ de remoção de corante. A relação entre a conversão de fóton incidente em corrente (IPCE) e a eficiência na remoção de contaminantes sob luz visível foi estudada por Zhang e Zhu. ${ }^{76}$ Esses autores mostraram que o catalisador PANI.CdS com maior conversão de fótons em corrente $(5,82 \%)$ promoveu remoção superior a $90 \%$ de azul de metileno, ao passo que apenas CdS apresentou IPCE em 3,27\% e remoção em torno de $60 \% .^{76}$

Em suma, a presença da polianilina como uma das fases de catalisadores compósitos promove maior separação e mais rápida transferência de cargas, bem como maior fotocorrente, IPCE e eficiência em fotocatálise frente aos catalisadores semicondutores aplicados isoladamente.

Adicionalmente, conhecer as espécies ativas nas reações de oxidação das moléculas do contaminante auxilia no entendimento das diferentes vias mecanísticas propostas. Portanto, alguns autores procederam a fotocatálise na presença de substâncias sequestrantes de buracos $\left(\mathrm{h}^{+}\right)$e radicais ( ${ }^{\circ} \mathrm{OH}$ e $\left.\mathrm{O}_{2}{ }^{-}\right)$e, assim, foi possível avaliar qual o impacto na remoção do contaminante em função da espécie ativa suprimida no processo de catálise. Conforme ocorre diminuição da eficiência catalítica, na presença de um determinado sequestrante, é possível identificar qual espécie ativa (radicais ou buracos) possui maior contribuição na oxidação das moléculas. ${ }^{6,43,54,55,76,78-81}$ Substâncias como EDTA-2Na (sal disódico do ácido etilenodiaminotetraacético), trietanolamina e oxalato de amônio são comumente empregadas para sequestrar buracos, álcool terc-butílico $(\mathrm{tBuOH})$ para radicais, e isopropanol e p-benzoquinona para radicais ${ }^{\circ} \mathrm{OH}$ e $\mathrm{O}_{2}{ }^{-}$, respectivamente. Associado ao estudo de espécies ativas por sequestrantes, a aplicação de técnicas como ressonância paramagnética eletrônica vem a agregar e aprimorar a compreensão do mecanismo através da identificação de radicais. ${ }^{6,14,82}$ É importante pontuar que as espécies ativas são dependentes de cada sistema (catalisador e condições de catálise), não sendo possível indicar, pelos trabalhos avaliados, uma concordância geral sobre quais são as espécies ativas preferenciais em sistemas com catalisadores baseados em polianilina.

Apesar da associação mais estudada em fotossensibilização com PANI se refira aos óxidos metálicos, tais como $\mathrm{TiO}_{2}$ e $\mathrm{ZnO}$, os mecanismos apresentados também representam o que ocorre em compósitos de polianilina com outros óxidos, sulfetos e materiais carbonáceos como o grafeno (GR) e óxido de grafeno (OG). ${ }^{56,68,73,76,83-86}$ Além disso, há catalisadores formados por mais de duas fases, resultando em associações como $\mathrm{PANI} / \mathrm{Fe}_{3} \mathrm{O}_{4} / \mathrm{SiO}_{2} / \mathrm{TiO}_{2}, \mathrm{PANI} / \mathrm{Fe}_{3} \mathrm{O}_{4} / \mathrm{ZnO}$ e $\mathrm{PANI} / \mathrm{Ag}_{3} \mathrm{PO}_{4} / \mathrm{OG}$. Em geral, as estratégias em adicionar outros materiais envolvem: (i) separação do catalisador do meio por sedimentação, imobilização em substratos, ou por campo magnético; (ii) melhor separação e transporte de cargas, como, por exemplo, através do uso materiais com alta afinidade por elétrons como OG e GR e (iii) aumento das interações entre contaminante e catalisador. $55,61,68,70,84,87-90$

Em linhas gerais, o mecanismo de fotossensibilização ocorre a partir da absorção de fótons por uma das fases do compósito (polianilina), e pela distribuição dos níveis de energia entre as fases, de modo que haja transferência de cargas, geração do par elétron/ buraco e, consequentemente, espécies reativas para fotocatálise de contaminantes.

\section{Catalisadores compósitos formados por polianilina}

O avanço e a divulgação de pesquisas envolvendo fotocatálise e polianilina na última década permitiram traçar um panorama geral sobre os diversos aspectos que estão sendo abordados dentro deste tema. A Tabela 1 sumariza os principais trabalhos em fotocatálise 
heterogênea que tiveram como objetivo estudar a influência da polianilina sobre $\mathrm{TiO}_{2}$. Os aspectos levantados foram: morfologia do compósito, condições operacionais de fotocatálise e eficiência de remoção do contaminante em estudo. Os valores de eficiência envolvendo apenas $\mathrm{TiO}_{2}$ não foram incluídos, tendo em vista que o desempenho dos catalisadores compósitos se mostrou superior.

\section{Principais parâmetros em fotocatálise com catalisadores baseados em polianilina}

O propósito deste tópico foi sistematizar as principais contribuições dos artigos apresentados na Tabela 1, abordando os aspectos específicos ao sistema de fotocatálise heterogênea que opera com catalisadores formados por polianilina. Apesar do enfoque em PANI. $\mathrm{TiO}_{2}$, existe ainda grande variedade de catalisadores formados por
PANI e outros óxidos metálicos, metais, sais e materiais carbonáceos. Destaca-se que materiais como $\mathrm{ZnO}, \mathrm{SiO}_{2}, \mathrm{MnO}_{2}, \mathrm{Cu}_{2} \mathrm{O}, \mathrm{CoFe}_{2} \mathrm{O}_{4}$, $\mathrm{CdS}, \mathrm{Ag}_{3} \mathrm{PO}_{4}, \mathrm{Ag}, \mathrm{Fe}_{2} \mathrm{O}_{3}$, grafeno e óxido de grafeno têm sido associados à polianilina em sistemas binários à quaternários com diferentes morfologias e condições fotocatalíticas. ${ }^{27,56,63,68,73,76,83-86,103,104}$ Alguns desses catalisadores foram contemplados nos itens a seguir, de modo a exemplificar fatores coincidentes para os mais diversos catalisadores formados por polianilina.

\section{Morfologia e quantidade de polianilina}

Em catalisadores compósitos com morfologia core-shell (casca-caroço) em que nanopartículas são encapadas por uma camada de polímero, a influência da espessura desta camada exerce papel fundamental no desempenho fotocatalítico (Figura 5A). A morfologia core-shell também pode ser encontrada em catalisadores em que

Tabela 1. Relação de estudos envolvendo fotocatálise com catalisadores baseados em polianilina e dióxido de titânio

\begin{tabular}{|c|c|c|c|}
\hline $\begin{array}{l}\text { Morfologia } \\
\text { PANI.TiO }_{2}\end{array}$ & $\begin{array}{c}\text { Condições de operacionais } \\
\text { (Fonte luminosa, pH, tempo de irradiação e } \\
\text { aeração) }\end{array}$ & Contaminante e Eficiência de catálise & Ref. \\
\hline Matriz de PANI com $\mathrm{TiO}_{2} 21 \mathrm{~nm}$ & Sódio de alta-pressão, $10 \mathrm{~min}$ & $\begin{array}{l}\text { Vermelho reativo } 195 \\
\text { Remoção }>95 \%\end{array}$ & 91 \\
\hline Nanofitas de Anatase encapadas por PANI & Xenônio e filtro, $2 \mathrm{~h}$ & $\mathrm{RB}^{\circledR} \sim 99 \%$ & 81 \\
\hline $\begin{array}{c}\text { Microesfera porosa de Anatase encapada } \\
\text { por PANI }\end{array}$ & Xenônio e filtro, $\mathrm{RB}^{\circledR}: 2 \mathrm{~h} \mathrm{AM}^{\#}: 2,5 \mathrm{~h}$ & $\mathrm{RB}^{\circledR} \mathrm{e}^{\mathrm{AM}^{*}}>95 \%$ & 78 \\
\hline $\begin{array}{c}\text { Anatase } \sim 28 \mathrm{~nm} \\
\text { core-shell }\end{array}$ & Solar, UV, pH 7, 2 h aeração & Remoção de benzeno 99\% & 71 \\
\hline $\begin{array}{l}\text { Anatase: grãos e Rutilo: agulhas, } \\
\text { imobilizados em Haloisita }\end{array}$ & Xenônio e filtro, $6 \mathrm{~h}$ & $\mathrm{RB}^{\circledR} \sim 77 \%$ & 67 \\
\hline Nanotubos de Anatase encapados por PANI & $\begin{array}{l}\text { Xenônio e filtro, } \mathrm{pH} 7,4 \\
140 \mathrm{~min} \\
\end{array}$ & $\mathrm{RB}^{\circledR} \sim 90 \%$ & 52 \\
\hline $\begin{array}{l}\text { Anatase: grãos e Rutilo: agulhas, } \\
\text { imobilizados em Haloisita }\end{array}$ & Xenônio e filtro, 6 h & $\mathrm{RB}^{\circledR} \sim 93 \%$ & 92 \\
\hline $\mathrm{TiO}_{2}$ microesfera-PANI & $\begin{array}{l}\text { Fluorescente: UV e Visível } \\
7,6 \mathrm{~s} \\
\end{array}$ & $\begin{array}{c}\text { Remoção de } \mathrm{NH}_{3}: \\
73 \% \text { (Vis) e } \sim 100 \% \text { (UV) }\end{array}$ & 93 \\
\hline $\begin{array}{c}\text { Anatase } 20-30 \text { nm e PANI sulfonada. } \\
\text { Core-shell }\end{array}$ & $\begin{array}{c}\text { Luz visível, } \mathrm{AM}^{\#}: 7 \mathrm{~h} \\
\text { Azul brilhante: } 5 \mathrm{~h}\end{array}$ & $\begin{array}{c}\text { Azul brilhante } \sim 98 \% \\
\mathrm{AM}^{\#} \sim 95 \%\end{array}$ & 66 \\
\hline Nanotubos de PANI 90-130 nm e $\mathrm{TiO}_{2} 10 \mathrm{~nm}$ & $\begin{array}{l}\text { Vapor de mercúrio, } \mathrm{pH} \text { natural da solução, } \\
2 \mathrm{~h}\end{array}$ & $\begin{array}{c}\text { AlM }^{\sigma}: 97,2 \% \\
\text { Alaranjado II: } 94,2 \% \\
\end{array}$ & 69 \\
\hline $\begin{array}{c}\text { Nanotubos de PANI decorados com Anatase } \\
\text { e Rutilo }\end{array}$ & Luz visível, $\mathrm{AM}^{\#}: 5$ h E.Coli.: 16 h & $\begin{array}{l}\text { Descoloração: } \mathrm{AM}^{\#} \sim 85 \% \\
\text { Inibição da E.Coli. } ~ 95 \%\end{array}$ & 21 \\
\hline $\begin{array}{c}\text { Anatase: } 100-200 \mathrm{~nm} . \\
\text { Bastões e matriz de PANI }\end{array}$ & Halógena e filtro, $\mathrm{pH} 8,0,2 \mathrm{~h}$, aeração & $\mathrm{AM}^{\#} \sim 76 \%$ & 94 \\
\hline $\begin{array}{l}\mathrm{TiO}_{2} \text {-P25 Core-shell } * \\
\text { Imobilizado em vidro }\end{array}$ & Fluorescente e filtro, $1 \mathrm{~h}$ aeração & Vermelho reativo $4 \sim 85 \%$ & 15 \\
\hline Anatase e Rutilo (14 e $19 \mathrm{~nm})$ & $\mathrm{UV}, 2 \mathrm{~h}$ & $\mathrm{AM}^{\#:} 73 \%$ & 95 \\
\hline Nanotubos de PANI.TiO $2-23 \mathrm{~nm}$ & $\mathrm{UV}, \mathrm{pH}$ natural, $2 \mathrm{~h}$ & Alaranjado II: $98.6 \%$ & 96 \\
\hline $\begin{array}{c}\text { Microesfera de nanobastões de Anatase. } \\
\text { Core-shell }\end{array}$ & $\begin{array}{l}\text { Xenônio e filtro: } 3 \mathrm{~h} \\
\text { UV: } 1 \mathrm{~h}\end{array}$ & $\begin{array}{l}\mathrm{AM}^{\#}: \text { (UV) k: } 0,0721 \mathrm{~min}^{-1} \\
\text { (Vis) k: } 0,0069 \mathrm{~min}^{-1}\end{array}$ & 73 \\
\hline $\begin{array}{l}\text { Microesfera de } \mathrm{TiO}_{2} \text { anatase }(1,3-6,1 \mu \mathrm{m}) \\
\text { e matriz de PANI. Imobilizado paredes do } \\
\text { reator }\end{array}$ & $\begin{array}{l}\text { Fluorescente: UV ou Visível, 0,2 min } \\
\text { Remoção de BTEX gasoso. }\end{array}$ & $\begin{array}{c}\text { Vis: Benzeno } \sim 58 \%, \\
\text { Tolueno } \sim 92 \%, \text { Etilbenzeno e Xileno } \\
94 \% \text {. } \\
\text { UV: BTEX }>90 \%\end{array}$ & 97 \\
\hline $\begin{array}{c}\text { Anatase } \sim 4 \text { - } 6 \mathrm{~nm} \text { e matriz de PANI. } \\
\text { Imobilizado em Polietileno Tereftalato } \\
(\mathrm{PET})\end{array}$ & $\mathrm{UV}, 2 \mathrm{~h}$ & $\mathrm{AM}^{\#} \sim 17 \%$ & 61 \\
\hline $\begin{array}{c}\text { Anatase } 4,5 \mathrm{~nm} \\
\text { Core-shell }^{*} \\
\end{array}$ & $\begin{array}{l}\text { Luz solar simulada, } 6 \text { h solução saturada } \\
\text { com } \mathrm{O}_{2}\end{array}$ & $\begin{array}{l}\mathrm{AM}^{\#} \sim 57 \% \\
\mathrm{RB}^{\circledR} \sim 96 \%\end{array}$ & 13 \\
\hline Anatase $23 \mathrm{~nm}$ e matriz de PANI & Luz solar, $\mathrm{pH} \mathrm{3,65 \textrm {min }}$ & $\mathrm{AM}^{\#} \sim 87 \%$ & 98 \\
\hline Anatase e PANI & Xenônio e filtro, 6 h & $\begin{array}{c}\text { 4-Clorofenol } \sim 30 \% \text { e COT } \text { COT }^{\theta}: 13,2 \% \\
\text { AlM }^{\sigma} \sim 96 \% \text { e COT } \\
\end{array}$ & 14 \\
\hline $\begin{array}{l}\text { Nanofibras de PANI decoradas com } \\
\text { nanoparticulas (Anatase e Rutilo) }\end{array}$ & $\begin{array}{c}\text { Halógena, } \mathrm{pH} 2,5 \\
\text { AM }^{\#:} 4 \text { h e RB }{ }^{\circledR}: 40 \text { min }\end{array}$ & $\begin{array}{l}\mathrm{AM}^{\#} \sim 30 \% \\
\mathrm{RB}^{\circledR} \sim 75 \%\end{array}$ & 12 \\
\hline
\end{tabular}


Tabela 1. Relação de estudos envolvendo fotocatálise com catalisadores baseados em polianilina e dióxido de titânio

\begin{tabular}{|c|c|c|c|}
\hline $\begin{array}{l}\text { Morfologia } \\
\text { PANI.TiO }_{2}\end{array}$ & $\begin{array}{c}\text { Condições de operacionais } \\
\text { (Fonte luminosa, pH, tempo de irradiação e } \\
\text { aeração) }\end{array}$ & Contaminante e Eficiência de catálise & Ref. \\
\hline $\mathrm{TiO}_{2}-\mathrm{P} 25$. Core-shell $*$ & Halógena e filtro, $2 \mathrm{~h}$ & $\mathrm{AlM}^{\sigma}: \sim 50 \%$ & 11 \\
\hline Microesfera porosa de Anatase. Core-shell ${ }^{*}$ & $\begin{array}{l}\text { Xenônio e filtro, } \mathrm{RB}^{\circledR}: 30 \mathrm{~min} \text { e } \\
\text { 4-clorofenol: } 7 \mathrm{~h}\end{array}$ & $\begin{array}{c}\text { 4-clorofenol: } \mathrm{COT}^{\theta}: \sim 46 \% \\
\text { RB }^{\circledR} \sim 99 \%\end{array}$ & 99 \\
\hline $\begin{array}{l}\text { Quitosana-PANI/PSS } / \mathrm{TiO}_{2}-\mathrm{P} 25 . \\
\text { Imobilizado em vidro. }\end{array}$ & UV e $350 \mathrm{~min}$ & $\mathrm{RB}^{\circledR} \sim 98 \%$ & 70 \\
\hline $\begin{array}{c}\text { PANI em esferas envoltas por bastões de } \\
\text { Rutilo. }\end{array}$ & Vapor de mercúrio e filtro, UV, $60 \mathrm{~min}$ & $\begin{array}{l}\text { Acetona (gás) } \\
\text { Visível: } \mathrm{k}: 0,0049 \mathrm{~min}^{-1} \\
\text { UV: } \mathrm{k}: 0,0068 \mathrm{~min}^{-1}\end{array}$ & 72 \\
\hline $\mathrm{TiO}_{2} / \mathrm{PDDA}^{\Delta} / \mathrm{PSS}^{\varphi} / \mathrm{PANI}$-fibras & Haleto metálico e filtro, $2 \mathrm{~h}$ & $\mathrm{AM}^{\#}: 30 \%$ & 20 \\
\hline $\begin{array}{l}\text { Filme PANI.TiO } \text { imobilizado em eletrodo } 20 \times 36 \mathrm{~mm}\end{array}$ & $\mathrm{UV}, 2 \mathrm{~h}$ & $\begin{array}{c}\text { 2,4 diclorofenol } \\
\mathrm{k}: 0,73 \times 10^{-2} \mathrm{~min}^{-1}\end{array}$ & 100 \\
\hline PANI.TiO ${ }_{2}-\mathrm{P} 25$ & Sódio de alta pressão e filtro, $2 \mathrm{~h}$ & $\mathrm{AM}^{\#}: 81,74 \%$ & 19 \\
\hline $\begin{array}{c}\text { Anatase.PANI em Core-shell* e nanobastões } \\
\text { de PANI. }\end{array}$ & $\mathrm{UV}, \mathrm{pH} 7,2 \mathrm{~h}$ & Verde malaquita: $99,4 \%$ & 101 \\
\hline Microfitas de $\mathrm{TiO}_{2}$ encapadas por PANI. & $\mathrm{UV}, \mathrm{pH} \mathrm{3,160 \textrm {min }}$ & $\mathrm{AlM}^{\sigma} \sim 97 \%$ & 74 \\
\hline Anatase.PANI & $\mathrm{UV}, \mathrm{pH} 2$ & $\begin{array}{c}\text { Vermelho Allura: } \\
\mathrm{k} \sim 5,310^{-3} \mathrm{~s}^{-1} \\
\text { Quinolina Amarela: } \\
\mathrm{k} \sim 7,110^{-3} \mathrm{~s}^{-1}\end{array}$ & 60 \\
\hline $\begin{array}{c}\mathrm{TiO}_{2} \mathrm{P} 25 \\
\text { Core-shell }\end{array}$ & $\begin{array}{c}\text { Xenônio e filtro: } \mathrm{AM}^{\#}: 5 \mathrm{~h} \text { e RB }{ }^{\circledR}: 100 \text { min } \\
\text { UV: } \mathrm{AM}^{\#:} 1 \mathrm{~h} \text { e } \mathrm{RB}^{\circledR}: 0,5 \mathrm{~h}\end{array}$ & $\begin{array}{c}\mathrm{AM}^{\#}: \mathrm{k}: 0,0071 \mathrm{~min}^{-1}(\mathrm{Vis}) \text { e } 0,091 \mathrm{~min}^{-1} \\
(\mathrm{UV}) \\
\mathrm{RB}^{\circledR}: \mathrm{k}: 0,0229 \min ^{-1}(\mathrm{Vis}) \text { e } 0,099 \mathrm{~min}^{-1} \\
(\mathrm{UV})\end{array}$ & 6 \\
\hline Anatase $\sim 14 \mathrm{~nm}$. Core-shell $*$ & Halógena e filtro, $5 \mathrm{~h}$ & Remoção de fenol 65\% & 7 \\
\hline Anatase $15 \mathrm{~nm}$. Core-shell $*$ & Solar, $2 \mathrm{~h}$ & Remoção de fenol 35\% & 22 \\
\hline Anatase $80-90 \mathrm{~nm}$. Core-shell $*$ & Solar e pH 6,8, $90 \mathrm{~min}$ & $\mathrm{AM}^{\#} \sim 80 \%$ & 102 \\
\hline Anatase $15 \mathrm{~nm}$. Core-shell $*$ & Solar, $2,5 \mathrm{~h}$ & $\mathrm{AlM}^{\sigma} \sim 99 \%$ & 18 \\
\hline
\end{tabular}

${ }^{\circledR} \mathrm{RB}$ : Rodamina $\mathrm{b},{ }^{,} \mathrm{AM}$ : azul de metileno, ${ }^{*}$ Core-shell: morfologia casca-caroço: PANI-TiO,${ }^{\circ} \mathrm{AlM}$ : Alaranjado de metila, ${ }^{\ominus} \mathrm{COT}$ : carbono orgânico total, ${ }^{\oplus} \mathrm{PSS}$ : poli (estireno sulfonato) de sal de sódio, ${ }^{, P D D A}$ : poli (cloreto de dialil-dimetil-amonio).

microesferas são encapadas com polianilina. ${ }^{55,64,78,99,105,106}$ Os estudos que abordaram essa morfologia demonstraram, por microscopia eletrônica de transmissão (MET) de alta resolução, que espessuras menores que $1 \mathrm{~nm}$ de polímero resultam em melhores resultados em fotocatálise. ${ }^{6,43,54,76,107}$ Radoicic et al. ${ }^{13}$ e Zhang et al. ${ }^{6}$ obtiveram maior eficiência catalítica através de $\mathrm{PANI}^{-T i O} \mathrm{O}_{2}$ com camada de aproximadamente $0,7 \mathrm{~nm}$, e assumiram que se tratava de uma monocamada de polianilina, considerando que a estrutura benzênica apresenta 0,5 $\mathrm{nm}$ de diâmetro. Semelhantemente, Pei et al. ${ }^{43}$ obtiveram cerca de $82 \%$ de remoção de COT na fotodegradação de 4-clorofenol no uso de PANI.ZnO com monocamada de polímero (espessura de $0,56 \mathrm{~nm}$ ). Zhang e Zhu ${ }^{76}$ atingiram redução de $90 \%$ de COT na fotocatálise de AM quando utilizado PANI.CdS com monocamada de polímero $(0,67$ $\mathrm{nm})$ sobre CdS. Razak, Nawi e Haitham ${ }^{15}$ mostraram que a espessura de $0,9 \mathrm{~nm}$ de PANI sobre óxido de titânio foi a mais favorável para a fotocatálise; valores de espessura maiores que este resultaram em decréscimo da eficiência catalítica, devido à baixa transmissão da luz em direção ao $\mathrm{TiO}_{2}$.

O planejamento da morfologia do catalisador foi pensado por Gu et al., ${ }^{12}$ de maneira que $\mathrm{TiO}_{2}$ estivesse livre para interagir mais facilmente com a luz e o contaminante, sem que houvesse a passivação da superfície do óxido ou dificuldade para a transmissão da luz no sistema. Portanto, a polianilina foi obtida inicialmente como nanofibras, e num segundo passo a síntese de nanoparticulas de $\mathrm{TiO}_{2}$ foi realizada decorando as mesmas (Figura 5B). Arranjos semelhantes a esse, utilizando nanotubos de PANI, foram elaborados por Jeong et al. ${ }^{21}$ Yang et al. ${ }^{69}$ e Cheng et al. ${ }^{96}$

A polianilina ainda pode ser obtida como massa contínua, servindo de matriz polimérica para suportar nanopartículas
(Figura 5C). ${ }^{56,75,79,108,109}$ Outras morfologias encontradas consistem em nanotubos, nanobastões ou fibras de óxidos encapados com nanopartículas de polianilina ${ }^{89}$ ou ainda como filme fino de PANI (Figura 5D). ${ }^{52,74,77,110-112}$

Adicionalmente, alguns trabalhos estudaram o efeito da presença de óxido de grafeno (OG) e grafeno (GR), obtendo catalisadores com nanotubos ${ }^{68}$ ou nanofibras ${ }^{84}$ de PANI distribuídas sobre folhas de GR e OG, respectivamente.

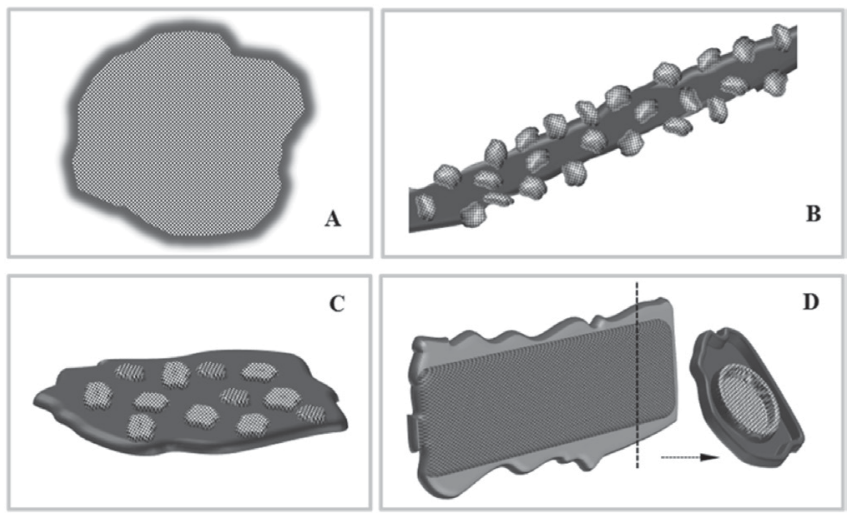

Figura 5. Diferentes morfologias de obtenção de catalisadores compósitos, onde a cor lisa representa a PANI e a textura o semicondutor. (A) Core-shell (casca-caroço), onde nanopartículas estão encapadas pela PANI, (B) nanotubos ou nanofibras de PANI decorados com nanopartículas, (C) matriz polimérica de PANI contendo nanopartículas, $e(D)$ nanotubos, nanobastões ou fibras de óxidos encapados com polianilina; detalhe da seção transversal 
A quantidade em massa de polímero é um parâmetro que também exerce influência no desempenho fotocatalítico dos catalisadores. Por isso, tem sido comumente abordada na literatura a relação mássica ótima de polianilina, de modo a beneficiar as interações entre as fases do compósito e contaminante. De modo geral, grande parte dos estudos indica valores abaixo de $3 \% \mathrm{~m} / \mathrm{m}$ de PANI no compósito. ${ }^{7,15,18,22,54,57,89} \mathrm{Li}$ e colaboradores ${ }^{57}$ prepararam catalisadores $\mathrm{TiO}_{2^{-}}$ PANI imobilizados em nanotubos de haloisita (aluminosilicato) e demonstraram que a massa de polianilina no compósito com maior eficiência fotocatalítica foi de 2,63\%. Quando catalisadores apresentaram massa de polímero inferior à otimizada, esses autores sugeriram que não houve formação de par elétron/buraco por unidade de tempo suficiente para promover remoção satisfatória do contaminante. Já em catalisadores com percentual de massa de PANI mais elevadas, os sítios superficiais do $\mathrm{TiO}_{2}$ estavam mais ocupados e os elétrons excitados não foram eficientemente transferidos para a $\mathrm{BC}$ do óxido. Assim, a recombinação elétron/buraco foi favorecida e a atividade fotocatalítica reduziu. Medidas de condutividade mostraram que conforme aumentou a massa de polianilina nos catalisadores, houve aumento de condutividade, porém este aumento não se traduziu em melhor atividade fotocatalítica, o que evidencia o efeito predominante do percentual da massa de PANI frente à condutividade do catalisador compósito. ${ }^{57}$ Liu et al. ${ }^{89}$ acrescentam que em catalisadores com massa de PANI superior a 2,3\% houve decréscimo da remoção de corante, decorrente da baixa transmissão de luz através do sistema, inviabilizando as transferências de cargas no compósito.

Associado ao estudo morfológico dos compósitos, a caracterização por espectroscopia fotoeletrônica de raios X (EFX) e infravermelho (IV) traz informações importantes sobre a interação interfacial entre o polímero e as demais fases. Interações do tipo ligação de hidrogênio e ligações covalentes como C-Ti-O ou $\mathrm{O}-\mathrm{C}=\mathrm{N}-\mathrm{Ti}$ contribuem para a transferência de carga entre as fases do compósito ( $\mathrm{PANI}_{\mathrm{TiO}}$ ) e, consequentemente, aumento da atividade fotocatalítica. ${ }^{6,12,14,31,61,72}$ Adicionalmente, essas interações garantem maior estabilidade térmica e física do catalisador. ${ }^{13,18,61} \mathrm{Em}$ certos trabalhos, a avaliação conjunta dos dados de IV e EFX mostraram que interações do tipo ligações de hidrogênio entre grupos amina e imina da polianilina e a superfície do $\mathrm{TiO}_{2}$ (contribuição de grupos $\mathrm{OH})$ estavam presentes em compósitos $\mathrm{PANI} . \mathrm{TiO}_{2}{ }^{12,61,72}$ Ligações covalentes entre a polianilina e $\mathrm{TiO}_{2}$ foram obtidas através de rotas sintéticas específicas, como a proposta por Li et al., ${ }^{61}$ na qual o precursor de nanopartículas de $\mathrm{TiO}_{2}$ (peróxido de titânio) também continha o potencial oxidante necessário para polimerizar a anilina. Desta forma, as cadeias de polianilina foram ancoradas no óxido através de ligações covalentes do tipo Ti-O-N-C e Ti-O-C.

\section{pH e Condutividade da polianilina}

A propriedade de condução elétrica da polianilina sobre a atividade fotocatalítica tem se apresentado essencial nos resultados finais de remoção de contaminantes. Em catalisadores compósitos, o papel da polianilina está ligado à sua condutividade e às heterojunções tipo n-p, e não somente à sensibilização similar ao de corantes. ${ }^{13,14,29,36,52}$ Como exemplo disto, o catalisador $\mathrm{PANI}_{-} \mathrm{TiO}_{2}-\mathrm{HA}$, submetido ao ácido nítrico, foi dopado para sal esmeraldina (forma condutora da PANI), e promoveu aumento da remoção de rodamina b de 44,46\% (desdopado) para 74,47\% (dopado). O mesmo processo fotocatalítico para o catalisador controle sem o polímero $\left(\mathrm{TiO}_{2}-\mathrm{HA}\right)$ resultou na remoção de $\sim 53 \%$ de corante, valor superior a todos compósitos com PANI desdopada.$^{57}$ Portanto, o desempenho do compósito em fotocatálise está diretamente relacionado com uso da polianilina dopada (sal esmeraldina). A capacidade de condução do polímero é importante na transferência de elétrons para a BC do óxido, reduzindo a taxa de recombinação e $/ \mathrm{h}^{+}$, e no aumento da atividade fotocatalítica. ${ }^{57}$
Conclusões semelhantes foram obtidas por Li e colaboradores, ${ }^{61}$ quando a maior remoção de AM foi atingida com o catalisador PANI. $\mathrm{TiO}_{2}$ com maior condutividade.

A dopagem da polianilina está relacionada à protonação de seus sítios básicos, que ocorre principalmente pela adição de ácidos inorgânicos (Figura 2). Por isso, o $\mathrm{pH}$ do meio possui forte influência sobre o estado de protonação (dopagem) e, consequentemente, na condutividade da PANI. Liao et $a l .{ }^{47}$ e Malinauskas ${ }^{113}$ destacaram que, em solução, a condutividade da polianilina reduz drasticamente quando o pH está acima de 3. Diante disso, o pH utilizado durante o processo de fotocatálise é de alta relevância na compreensão das interações entre as fases do compósito e no mecanismo geral de fotossensibilização com polianilina.

Lin e $\mathrm{Wu}^{77}$ associaram o nível de dopagem da polianilina em catalisadores PANI.ZnO-nanotubos e a eficiência fotocatalítica em diferentes valores de $\mathrm{pH}$. Esses pesquisadores demonstraram por espectroscopia de impedância eletroquímica que o nível de dopagem da polianilina diminui conforme o aumento do $\mathrm{pH}$, especialmente para valores acima de 7 . A capacidade de remoção de rodamina b foi mais pronunciada quando a fotocatálise procedeu em $\mathrm{pH}$ 2,5, situação na qual o polímero apresentou maior nível de dopagem.

Ahmad e Mondal, ${ }^{98}$ na aplicação de PANI.TiO $_{2}$ como catalisador, encontraram pH ótimo em 3 com 87,6\% de remoção de AM, enquanto que em pH 12 houve apenas 29\%. Apesar desses resultados, o entendimento das relações entre $\mathrm{pH}$, condutividade e interações entre fases não foi explorado. Situação similar foi apresentada por Ghavami $e t$ $a l .{ }^{87}$ em estudos envolvendo o catalisador OG/PANI/TiO $/ \gamma \mathrm{Fe}_{2} \mathrm{O}_{3}$, que mostrou maior eficiência de remoção de rodamina b em pH 3 (94\%) do que em pH 9 (65\%).

Num estudo cinético de fotodegradação de corantes, Salem, Al-Ghonemiy e $\mathrm{Zaki}^{60}$ demonstraram que a constante de velocidade (k) reduziu consideravelmente quando o meio reacional esteve com $\mathrm{pH}$ ajustado em 8. Os pesquisadores atribuíram a esse resultado a diminuição da capacidade do polímero em adsorver os corantes, em função da mudança de carga superficial (desprotonação) que ocorre quando o sal esmeraldina é convertido à base esmeraldina em valores de $\mathrm{pH}$ elevados.

Rasoulifard et al. ${ }^{65}$ também relacionaram o efeito do $\mathrm{pH}$ à mudança de carga superficial do catalisador Quitosana/PANI/CdS. A degradação fotocatalítica do corante RB19 foi mais pronunciada em valores de $\mathrm{pH}$ abaixo do ponto de carga zero do catalisador $\left(\mathrm{pH}_{\mathrm{Pcz}}\right.$ 7,2 ), situação na qual foi favorecida a adsorção do corante (carga negativa) à superfície positiva do Quitosana/PANI/CdS.

Em contrapartida, alguns trabalhos mostraram uma tendência diferente, situações nas quais valores de $\mathrm{pH}$ mais elevados foram mais adequados. $\mathrm{O}$ estudo realizado por Sabbaghi, Mohammadi e Ebadi $^{71}$ avaliou a remoção de benzeno por PANI.TiO 2 em pH 3, 5, 7, 9 e 11 sob luz solar. Nesse caso, a viabilidade do sistema operar em pH 7 foi comprovada quando a remoção de benzeno foi cerca de $5 \%$ superior à encontrada em $\mathrm{pH} 3$. Nabid et al., ${ }^{59}$ na remoção de alaranjado de metila por $\mathrm{PANI} . \mathrm{TiO}_{2} \cdot \mathrm{ZnO} \cdot \mathrm{Fe}_{3} \mathrm{O}_{4}$, encontraram condições mais favoráveis em pH acima de 7 devido à adsorção ser desfavorecida pela repulsão entre as cargas iguais que o catalisador e corante apresentam em $\mathrm{pH}$ ácido.

Conforme apresentado na Tabela 1, apenas 24\% dos trabalhos publicados informam as condições de $\mathrm{pH}$ nos ensaios de fotocatálise e poucos desses trabalhos descrevem a otimização desse parâmetro. A compreensão desse parâmetro ainda se revela um campo fértil para estudos futuros.

\section{Contaminantes}

No que se refere ao contaminante modelo submetido à fotocatálise, a principal abordagem tem sido a capacidade de ser adsorvido 
pela polianilina na superfície do catalisador. Os estudos que procederam a fotocatálise com corantes sugerem que o caráter aniônico ou catiônico destes substratos e a carga do polímero quando dopado ou desdopado (sal ou base esmeraldina, Figura 2) influenciam na adsorção e no desempenho de fotodegradação de corantes. . $^{13,60,65,70,89}$ Neste âmbito, conforme já abordado no item anterior, o estudo do efeito $\mathrm{pH}$ na fotocatálise torna-se relevante na compreensão da adsorção de diversos contaminantes em catalisadores baseados em polianilina.

A capacidade de absorção de radiação visível pelo contaminante é outro importante aspecto a ser considerado em pesquisas com catalisadores fotossensibilizados. A exemplo disso, existem corantes como o alaranjado de metila, azul de metileno e rodamina $b$, que são amplamente utilizados em ensaios de fotocatálise. No entanto, quando a molécula do corante é irradiada pela luz visível, o elétron em HOMO é promovido para LUMO e, então, a molécula pode transferir elétrons para a banda de condução (BC) do óxido, resultando em espécies reativas que degradam o próprio corante. Esse mecanismo é conhecido por fotossensibilização por corantes,,${ }^{9,10,34,35}$ e é semelhante às transferências de carga que ocorrem na fotossensibilização por polímeros condutores (Figura 3A). Por essa razão, na avaliação de desempenho de catalisadores compósitos sensibilizados, o uso de contaminantes que em fase aquosa sejam incolores é recomendado para a melhor compreensão de mecanismo de fotossensibilização, sem que haja interferência por parte do contaminante. ${ }^{9}$

Wang et al. ${ }^{19}$ observaram que a eficiência na remoção de azul de metileno (AM) sob luz visível ocorreu pela fotossensibilização do $\mathrm{TiO}_{2}$ pelo corante, enquanto que nos ensaios com o compósito PANI.TiO ${ }_{2}$ houve contribuição de ambos, corante e polianilina, na sensibilização do óxido.

A influência do corante também foi abordada por Gülce et al. ${ }^{56}$ num sistema de fotocatálise com PANI e PANI.CdO sob luz solar. Os pesquisadores sugeriram que as moléculas do corante AM excitadas pela luz solar promoveram a fotossensibilização da PANI e PANI. $\mathrm{CdO}$, o que resultou na remoção de COT em $52 \%$ e $71 \%$, respectivamente. As equações 11 a 16 foram propostas para o efeito do corante, em que SCM refere-se ao catalisador PANI ou PANI.CdO, $h v_{\text {(solar) }}$ energia luminosa, $\mathrm{e}_{\mathrm{BC}}^{-} \mathrm{e} \mathrm{h}^{+}{ }_{\mathrm{BV}}$ elétron e buraco, e corante ${ }_{\mathrm{ads}}$ molécula de corante adsorvido na superfície do catalisador. ${ }^{56}$

Corante $_{\text {ads }}+h v_{\text {(solar) }} \rightarrow$ Corante $_{\text {ads }}^{*}$

Corante $_{\mathrm{ads}^{*}}{ }^{+}+\mathrm{SCM} \rightarrow$ Corante $_{\mathrm{ads}^{+}}+{ }^{+}\left(\mathrm{e}^{-} \mathrm{BC}_{\mathrm{SCM}}\right.$

$\left(\mathrm{e}_{\mathrm{BC}}^{-}\right)_{\mathrm{SCM}}+\mathrm{O}_{2} \rightarrow \mathrm{O}_{2}^{-} \stackrel{2 \mathrm{H}^{+}}{\longrightarrow} \cdot \mathrm{OH}+{ }^{-} \mathrm{OH}$

Corante + radicais $\left(\mathrm{O}_{2}^{-}, \mathrm{HO}^{\circ}\right) / \mathrm{H}_{2} \mathrm{O}_{2} \rightarrow$ produtos de degradação

Corante $_{\text {ads }}+\left(\mathrm{h}^{+}{ }_{\mathrm{BV}}\right)_{\mathrm{SCM}} \rightarrow$ Corante $_{\text {ads }}$. $^{+}$

Corante $_{\text {ads }}{ }^{++} \rightarrow$ produtos de degradação

De acordo com essas reações, a degradação do AM é potencializada pela transferência de elétrons para a BC do compósito, gerando espécies radicalares que degradam o próprio corante. Somado a essa via de remoção do AM, em paralelo devem ocorrer reações com $\mathrm{e}^{-} \mathrm{eh}^{+}$gerados no catalisador devido à radiação incidente (Figura 4). ${ }^{56}$ Conclusões similares a essas foram relatadas por Eskizeybek et al. ${ }^{114} \mathrm{e}$ Yang e Luan $^{115}$ na remoção de corantes num sistema sob luz solar utilizando PANI.ZnO, e luz visível utilizando PANI.Bi2SnTiO7, respectivamente.

Apesar da interferência do corante no mecanismo de fotossensibilização, as interações das moléculas do corante com o catalisador não são tão favorecidas quanto aquelas obtidas num material compósito de polianilina e $\mathrm{TiO}_{2}$, por exemplo. Pelaez et al. ${ }^{9}$ e Pei e $\mathrm{Luan}^{34}$ frisam que o mecanismo é dependente da transferência eletrônica interfacial, e por isso é influenciado pela natureza do semicondutor, corante e a interação entre eles. Assim, o sinergismo e a estabilidade de um compósito (catalisador e PC) são mais acentuados que aquele entre catalisador e corante. ${ }^{11,12,34,36}$
Conforme levantamento apresentado na Tabela 1, os corantes ainda são os contaminantes modelo mais utilizados, sendo que $81 \%$ dos artigos contemplaram corantes na avaliação de catalisadores PANI. $\mathrm{TiO}_{2}$. Em virtude do que se apresentou sobre fotossensibilização por corantes, ainda há uma vasta área de estudo em catalisadores compósitos fotossensibilizados frente a contaminantes incolores em solução aquosa. Além disso, é necessário ampliar cada vez mais pesquisas em fotocatálise quanto à remoção de contaminantes emergentes (por exemplo fármacos), compreendendo os processos de degradação de uma variedade maior de moléculas do que apenas àquelas tradicionalmente estudadas, como são os corantes.

\section{Aeração}

A importância do gás oxigênio dissolvido $\left(\mathrm{O}_{2}\right)$ relaciona-se principalmente com a supressão da recombinação do par elétron/buraco a partir da acepção de elétrons na banda de condução do semicondutor (Equações 2 e 8). Além disso, contribui para o aumento de espécies reativas, como o radical hidroxila, previne reações de redução, e promove a mineralização e o aumento da taxa fotodegradação de compostos intermediários. ${ }^{10,116}$

A Figura 3A mostra que, na principal via mecanística de fotossensibilização de nanocompósitos baseados em polianilina, oxigênio dissolvido apresenta função marcante na geração de espécies reativas. Neste âmbito, o parâmetro aeração mostra-se relevante em estudos de fotossensibilização. Contudo, nos trabalhos levantados para PANI. $\mathrm{TiO}_{2}$ (Tabela 1), apenas uma pequena porção contemplou a aeração ou estudou seus efeitos.

Este parâmetro foi avaliado por Lin et al. ${ }^{14}$ para $\mathrm{PANI}^{\mathrm{TiO}}{ }_{2}$, em estudo que demonstrou que a aeração constante durante todo o período de irradiação promoveu o aumento da velocidade de remoção do corante alaranjado de metila, decorrente da geração de uma variedade espécies reativas. Nesse trabalho também foi estudada a ausência de oxigênio dissolvido, através da purga da solução com $\mathrm{N}_{2}$. Como resultado, foi observada uma reação de redução e a formação de hidrazina. Adicionalmente, Pei et al. ${ }^{43}$ também mostraram a formação de derivados de hidrazina num sistema com purga de $\mathrm{N}_{2}$, o que mostrou o efeito indispensável do oxigênio dissolvido na completa remoção de alaranjado de metila por PANI.ZnO.

Zhang, Zong e Zhu ${ }^{54}$ e Zhang et al. ${ }^{6}$ demonstraram, num estudo com sequestrantes, que catalisadores PANI.ZnO e PANI.TiO ${ }_{2}$, respectivamente, sob luz visível, promoveram a fotocatálise de AM através de radicais $\left({ }^{\circ} \mathrm{OH} \mathrm{e} \mathrm{O}_{2}{ }^{-}\right)$. Tal resultado reforça a principal via mecanística de fotossensibilização apresentada na Figura 3A. Além desses trabalhos, ainda há outros que mostram essa tendência. ${ }^{79,80}$ Portanto, é prioritário que esse parâmetro operacional seja cada vez mais explorado em pesquisas com catalisadores sensibilizados por polianilina.

\section{Fonte luminosa}

O advento do uso de polímeros condutores em fotocatálise, como a polianilina, está motivado pela crescente necessidade de fontes renováveis de energia em tratamento de efluentes. Propriedades como alta absortividade de luz visível e condutividade elétrica conferem à polianilina potencial para atuar como fotossensibilizador sob luz solar em sistemas de fotocatálise heterogênea..$^{711-15,68}$ Portanto, a escolha da fonte luminosa nas pesquisas em fotocatálise é crucial para a real avaliação do desempenho de catalisadores sob luz solar. Lâmpadas de xenônio e halógena são as que melhor representam a luz solar, pois possuem emissão em grande parte na região do visível (vis) e infravermelho próximo e menor parcela na região do ultravioleta (UV). ${ }^{9,117}$ Em conformidade com esse contexto, a Tabela 1 mostra que $51 \%$ dos trabalhos publicados especificaram o uso de luz solar (natural ou simulada), lâmpada de xenônio ou halógena. Adicionalmente, com intuito avaliar o efeito apenas da luz visível, grande parte das 
pesquisas utilizaram filtros específicos para remover toda emissão de UV que as lâmpadas poderiam emitir.

Lin et al. ${ }^{14}$ procederam a fotocatálise de alaranjado de metila sob lâmpada de xenônio com dois tipos de filtros, um permitindo a passagem de $420 \mathrm{~nm}<\lambda<800 \mathrm{~nm}$ e outro $550 \mathrm{~nm}<\lambda<800 \mathrm{~nm}$, com o intuito de avaliar o efeito da fração visível no desempenho de compósitos $\mathrm{PANI}_{\text {TiO }}$ frente ao óxido isolado. Os pesquisadores mostraram que com o espectro menor de emissão de luz, a remoção do corante pelo compósito passou de $96 \%$ para $85 \%$, já o efeito sob o $\mathrm{TiO}_{2}$ foi maior (redução de $65 \%$ para $14 \%$ ), ficando claro o potencial da polianilina em fotossensibilizar o óxido de titânio.

Razak, Nawi e Haitham ${ }^{15}$ utilizaram lâmpada fluorescente e catalisador $\mathrm{TiO}_{2} / \mathrm{PANI}$ imobilizado em vidro na remoção fotocatalítica do corante vermelho reativo 4 e realizaram ensaios com e sem filtro para UV. Os resultados mostraram que, quando há presença de todo espectro de emissão da lâmpada (UV e vis), a descoloração foi cerca de $99 \%$ em 60 minutos. Já no ensaio realizado com filtro (apenas luz visível), o valor obtido foi aproximadamente $78 \%$ no mesmo tempo de irradiação. Apesar desse resultado não ter sido abordado pelos autores, tem-se a evidência do efeito predominante da fração visível na eficiência fotocatalítica, o que reflete a capacidade de fotossensibilização da PANI.

A faixa de comprimento de onda emitida pela fonte luminosa é determinante sobre as vias mecanísticas em que o processo de fotocatálise ocorre, conforme já abordado nas equações 1 a 10 e ilustrado nas Figuras 3 e 4. Entretanto, ainda é importante ressaltar que a performance do sistema fotocatalítico também é função da potência (W) da fonte luminosa artificial e da forma como esta está posicionada em relação a solução de contaminantes. Já em sistemas sob radiação solar, a performance é função das condições climáticas e do horário do dia em que a fotocatálise é aplicada. ${ }^{5,10,116,118}$

Diante disso, para auxiliar a compreensão quanto ao comprimento de onda da fonte, alguns pesquisadores se dedicaram em avaliar, paralelamente, o desempenho de seus catalisadores sob lâmpadas com emissão no visível e também sob aquelas que emitem majoritariamente no UV. $., 11,12,54,73,79$ Xiong et al.,${ }^{79}$ por exemplo, mostraram que a remoção de alaranjado de metila por $\mathrm{CoFe}_{2} \mathrm{O}_{4}$.PANI sob luz UV, proveniente de uma lâmpada de vapor de mercúrio $(500 \mathrm{~W})$, ocorreu em menor tempo e com maior percentual de remoção em relação ao ensaio com apenas luz visível a partir de uma lâmpada de xenônio $(500 \mathrm{~W})$ e filtro. Nesse estudo, as diferenças foram marcantes: sob luz UV em 120 minutos houve aproximadamente $100 \%$ de remoção do corante, enquanto que, sob luz visível, cerca de $84 \%$ foram removidos em 9 horas de ensaio.

Zhang et al., ${ }^{6}$ com catalisador $\mathrm{PANI}^{\mathrm{T} T i \mathrm{O}_{2}}$, observaram que a constante de velocidade $(k)$ e a remoção de azul de metileno sob luz UV (11 W, $\lambda=254 \mathrm{~nm}$ ) foram $0,0091 \mathrm{~min}^{-1}$ e cerca de $99 \%$ em 75 minutos, ao passo que, sob luz visível ( $500 \mathrm{~W}$ xenônio e filtro), encontraram $0,0071 \mathrm{~min}^{-1}$ e cerca de $80 \%$ em 300 minutos. Em outro estudo, optou-se por fixar o tempo de fotocatálise com $\mathrm{PANI}^{\mathrm{TiO}} \mathrm{T}_{2} \mathrm{em}$ 120 minutos e então avaliar o desempenho na remoção de alaranjado de metila sob uma lâmpada halógena de $50 \mathrm{~W}$ associada a um filtro e lâmpada UV de 30 W. Decorrido o mesmo tempo de ensaio, houve remoção de 49,9\% $\left(\mathrm{k}=0,0037 \mathrm{~min}^{-1}\right)$ e $92,9 \%\left(\mathrm{k}=0,0235 \mathrm{~min}^{-1}\right)$ do corante sob luz visível e UV, respectivamente. ${ }^{11}$ Conforme já citado anteriormente, nesse caso, a luz UV também promove transferências de carga no óxido metálico semicondutor (Figura 4), gerando maior densidade de corrente e espécies reativas, o que se traduz em melhores condições cinéticas e remoção de contaminante. ${ }^{13,43,60,61,66}$ Portanto, sob luz UV, a contribuição do óxido metálico é significativa no desempenho fotocatalítico. Essa observação foi demonstrada por Zhang, Zong e Zhu, ${ }^{54}$ quando obtiveram aproximadamente 8 vezes mais fotocorrente pelo catalisador PANI.ZnO (suportado em ITO indium tin oxide) sob luz UV em relação àquela obtida sob luz visível.
Os resultados desses autores mostraram que a remoção de AM foi mais pronunciada sob luz UV, correlacionando a maior geração de fotocorrente ao melhor desempenho fotocatalítico.

\section{Capacidade de reuso}

Por se tratar de uma nova linha de catalisadores compósitos, há necessidade de se investigar o desempenho destes materiais ao longo de repetidos ciclos de fotocatálise. Avaliar essa capacidade de reuso é fundamental na identificação da estabilidade e longevidade desses catalisadores. É importante salientar que, além da resposta em remoção de contaminantes, a estabilidade e longevidade dos catalisadores estão relacionadas à estrutura química e física do catalisador após o reuso. Por isso, para uma avaliação apropriada da capacidade de reuso, há necessidade de associar a caracterização do material ao seu desempenho em fotocatálise após alguns ciclos de reuso.

Li et al. ${ }^{67}$ demonstraram redução gradual da atividade catalítica (cerca de 12\%) ao longo de 4 ciclos de reuso do catalisador PANI. $\mathrm{TiO}_{2}$ imobilizado em nanotubos de haloisita, porém, enfatizam boa sedimentabilidade e que não houve limpeza do material entre os ciclos. O reuso do catalisador $\mathrm{TiO}_{2} \cdot \mathrm{SiO}_{2}$ nanofibras/membrana e PANI, elaborado por Liu et al., ${ }^{89}$ apresentou decréscimo da atividade fotocatalítica ( $87 \%$ para $70 \%$ ). Contudo, os autores pontuam que o material ainda possui bom desempenho, principalmente devido ao reuso ter sido continuado sem tratamento prévio, e ainda acrescenta imagens de microscopia eletrônica de varredura (MEV) comprovando a estabilidade do material. Alto desempenho no reuso, após 10 ciclos, foi obtido por Razak, Nawi e Haitham, ${ }^{15}$ a partir de catalisadores $\mathrm{TiO}_{2} /$ PANI/ENR/PVC imobilizados em lâminas de vidro tendo policloreto de vinila (PVC) e borracha natural epoxidada (ENR) como adesivos. Wang et al. ${ }^{62}$ obtiveram o catalisador PANI.Bi ${ }_{2} \mathrm{WO}_{6}$ imobilizado em malha de aço, o qual após 5 ciclos manteve seu desempenho fotocatalítico inalterado.

A capacidade de reúso para sistemas fotocatalíticos com catalisador disperso também tem sido reportada na literatura. ${ }^{7,12,14,43,59,73,78} \mathrm{~A}$ exemplo disto, Leng et al.,${ }^{73} \mathrm{Gu}$ et al. ${ }^{12}$ Lin et al.,${ }^{14} \mathrm{Li}$ et al. ${ }^{7}$ e Deng et al. ${ }^{78}$ demonstraram decréscimo inferior a $10 \%$ em fotocatálise após 5 ciclos de reuso. Deng et al. ${ }^{78}$ ainda salienta que não houve limpeza do catalisador entre os ciclos, ressaltando ainda mais a capacidade de reuso deste material. Adicionalmente, Zhang et al..$^{55}$ e Kim, Jung e Lee ${ }^{110}$ mostraram redução inferior a $10 \%$ na remoção de corantes, após 7 e 3 ciclos, respectivamente. Em contrapartida, existem outros trabalhos com redução de eficiência mais pronunciada ao longo dos ciclos de reuso, chegando a valores entre 20 a $30 \% .^{59,114}$

Leng et al. ${ }^{73}$ através de espectroscopia infravermelho (IV) e microscopia eletrônica de transmissão (MET), mostraram estabilidade do material após reuso, porém, houve redução da área superficial (BET) em decorrência da adsorção de produtos de reação como $\mathrm{NH}_{4}{ }^{+}$ e $\mathrm{NO}_{3}{ }^{-}$. Através da caracterização por IV dos catalisadores após vários ciclos de reuso, Gu et al. ${ }^{12} \mathrm{Li}$ et al.,${ }^{7} \mathrm{Nabid}$ et al. ${ }^{59}$ e Eskizeybek et $a l .{ }^{114}$ também mostraram a estabilidade e capacidade de reuso de seus materiais.

De modo geral, após alguns ciclos de reuso a eficiência catalítica tende a reduzir. No entanto, a capacidade de reuso é relativa e dependente do sistema fotocatalítico utilizado (catalisador e condições experimentais), podendo revelar, em muitos casos, o potencial dos catalisadores baseados em polianilina de serem estáveis e eficientes quando reutilizados.

\section{CONCLUSÕES E PROSPECÇÃO PARA PESQUISAS FUTURAS}

A performance da polianilina em catalisadores compósitos tem sido marcante na fotossensibilização frente à luz visível. Para 
catalisadores tradicionalmente inativos nessa faixa do espectro solar, uma nova estratégia surge pela associação com polímeros condutores, em especial a polianilina.

O papel da PANI transcende a absorção de fótons e contribui na separação e transporte de cargas, e minimização da recombinação elétron/buraco. A grande variedade de associações com a polianilina sejam óxidos ou outros materiais, bem como as diferentes morfologias e características, e as mais diversas condições operacionais, evidenciam a versatilidade e o potencial deste polímero em contribuir para o melhor desempenho em sistemas fotocatalíticos. No entanto, ainda há um vasto campo de estudo a ser explorado, principalmente no que se refere: (i) à remoção de contaminantes emergentes, (ii) ao planejamento fatorial de condições operacionais, (iii) à fotocatálise em escala piloto e sistemas com catalisador imobilizado, e (iv) à compreensão da relação entre estrutura e propriedade fotocatalítica. Catalisadores apenas orgânicos, formados por PANI e GO ou GR, possuem perspectivas futuras interessantes por favorecem a mobilidade de cargas e reduzirem a recombinação elétron/buraco.

Catalisadores baseados em polianilina têm apresentado resultados promissores na fotocatálise de contaminantes, o que representa seu potencial em tratamento de efluentes sob luz solar, bem como a sua consolidação como uma nova classe de fotossensibilizadores.

\section{REFERÊNCIAS}

1. Alfano, O. M.; Bahnemann, D.; Cassano, A. E.; Dillert, R.; Goslich, R.; Catal. Today 2000, 58, 199.

2. Fujishima, A.; Zhang, X.; Tryk, D. A.; Int. J. Hydrogen Energy 2007, 32, 2664.

3. Homem, V.; Santos, L.; J. Environ. Manage. 2011, 92, 2304.

4. Srikanth, B.; Goutham, R.; Narayan, R. B.; Ramprasath, A.; Gopinath, K. P.; Sankaranarayanan, A. R.; J. Environ. Manage. 2017, 200, 60.

5. Parra, S.; Malato, S.; Pulgarin, C.; Appl. Catal., B 2002, 36, 131.

6. Zhang, H.; Zong, R.; Zhao, J.; Zhu, Y.; Environ. Sci. Technol. 2008, 42, 3803.

7. Li, X.; Wang, D.; Cheng, G.; Luo, Q.; An, J.; Wang, Y.; Appl. Catal., B 2008, 81, 267.

8. Mourão, H. A. J. L.; De Mendonça, V. R.; Malagutti, A. R.; Ribeiro, C.; Quim. Nova 2009, 32, 2181.

9. Pelaez, M.; Nolan, N. T.; Pillai, S. C.; Seery, M. K.; Falaras, P.; Kontos, A. G.; Dunlop, P. S. M.; Hamilton, J. W. J.; Byrne, J. A.; O'Shea, K.; Entezari, M. H.; Dionysiou, D. D.; Appl. Catal., B 2012, 125, 331.

10. Malato, S.; Fernández-Ibáñez, P.; Maldonado, M. I.; Blanco, J.; Gernjak, W.; Catal. Today 2009, 147, 1.

11. Olad, A.; Behboudi, S.; Entezami, A. A.; Bull. Mater. Sci. 2012, 35, 801.

12. Gu, L.; Wang, J.; Qi, R.; Wang, X.; Xu, P.; Han, X.; J. Mol. Catal. A: Chem. 2012, 357, 19.

13. Radoičić, M.; Šaponjić, Z.; Janković, I. A.; Ćirić-Marjanović, G.; Ahrenkiel, S. P.; Čomor, M. I.; Appl. Catal., B 2013, 136-137, 133.

14. Lin, Y.; Li, D.; Hu, J.; Xiao, G.; Wang, J.; Li, W.; Fu, X.; J. Phys. Chem. C 2012, 116, 5764

15. Razak, S.; Nawi, M. A.; Haitham, K.; Appl. Surf. Sci. 2014, 319, 90.

16. Gou, Y.; Chen, D.; Su, Z.; Appl. Catal., A 2004, 261, 15.

17. Senadeera, G. K. R.; Kitamura, T.; Wada, Y.; Yanagida, S.; J. Photochem. Photobiol., A 2004, 164, 61.

18. Li, J.; Zhu, L.; Wu, Y.; Harima, Y.; Zhang, A.; Tang, H.; Polymer 2006, 47, 7361.

19. Wang, F.; Min, S.; Han, Y.; Feng, L.; Superlattices Microstruct. 2010, 48, 170.

20. Prastomo, N.; Ayad, M.; Kawamura, G.; Matsuda, A.; J. Ceram. Soc. Jpn. 2011, 119, 342.

21. Jeong, W.-H.; Amna, T.; Ha, Y.-M.; Hassan, M. S.; Kim, H.-C.; Khil, M.-S.; Chem. Eng. J. 2014, 246, 204.
22. Li, X.; Wang, D.; Luo, Q.; An, J.; Wang, Y.; Cheng, G.; J. Chem. Technol. Biotechnol. 2008, 83, 1558.

23. Salvatierra, R. V.; Oliveira, M. M.; Zarbin, A. J. G.; Chem. Mater. 2010 , 22, 5222

24. Tian, Z.; Yu, H.; Wang, L.; Saleem, M.; Ren, F.; Ren, P.; Chen, Y.; Sun, R.; Sun, Y.; Huang, L.; RSC Adv. 2014, 4, 28195.

25. Su'ait, M. S.; Rahman, M. Y. A.; Ahmad, A.; Sol. Energy 2015, 115, 452.

26. Abdulalmohsin, S.; Li, Z.; Mohammed, M.; Wu, K.; Cui, J.; Synth. Met. 2012, 162, 931.

27. Nsib, M. F.; Saafi, S.; Rayes, A.; Moussa, N.; Houas, A.; J. Energy Inst. 2015, 1.

28. Zhang, S.; Chen, Q.; Jing, D.; Wang, Y.; Guo, L.; Int. J. Hydrogen Energy 2012, 37, 791.

29. Riaz, U.; Ashraf, S. M.; Kashyap, J.; Mater. Res. Bull. 2015, 71, 75.

30. Pathania, D.; Sharma, G.; Kumar, A.; Kothiyal, N. C.; J. Alloys Compd. 2014, 588, 668

31. Reddy, K. R.; Hassan, M.; Gomes, V. G.; Appl. Catal., A 2015, 489, 1.

32. Liu, X. J.; Guo, Z. P.; Jin, C. Q.; Synth. Met. 1991, 41-43, 1139.

33. Peralta-Zamora, P.; Moraes, S. G. de; Reyes, J.; Durán, N.; Polym. Bull. 1996, 37, 531.

34. Pei, D.; Luan, J.; Int. J. Photoenergy 2012, 2012, 1.

35. Tahir, M.; Amin, N. S.; Energy Convers. Manage. 2013, 76, 194.

36. Ansari, M. O.; Khan, M. M.; Ansari, S. A.; Cho, M. H.; J. Saudi Chem. Soc. 2015, 19, 494.

37. Lee, K.; Cho, S.; Park, S. H.; Heeger, a J.; Lee, C.-W.; Lee, S.-H.; Nature 2006, 441, 65.

38. Bredas, J. L.; Street, G. B.; Acc. Chem. Res. 1985, 18, 309.

39. MacDiarmid, A. G.; Epstein, A. J.; Synth. Met. 1995, 69, 85

40. Xia, Y.; Wiesinger, J. M.; MacDiarmid, A. G.; Epstein, A. J.; Chem. Mater. 1995, 7, 443.

41. Chinn, D.; Dubow, J.; Li, J.; Janata, J.; Josowicz, M.; Chem. Mater. 1995, 7, 1510.

42. Huang, W.-S.; Humphrey, B. D.; MacDiarmid, A. G.; J. Chem. Soc., Faraday Trans. 1 1986, 82, 2385.

43. Pei, Z.; Ding, L.; Lu, M.; Fan, Z.; Weng, S.; Hu, J.; Liu, P.; J. Phys. Chem. C 2014, 118, 9570.

44. Stejskal, J.; Dybal, J.; Trchová, M.; Synth. Met. 2014, 197, 168.

45. Schnitzler, D. C.; Zarbin, A. J. G.; J. Braz. Chem. Soc. 2004, 15, 378.

46. Huang, W. S.; MacDiarmid, A. G.; Polymer 1993, 34, 1833.

47. Liao, Y.; Zhang, C.; Zhang, Y.; Strong, V.; Tang, J.; Li, X.; Kalantarzadeh, K.; Hoek, E. M. V; Wang, K. L.; Kaner, R. B.; Nano Lett. 2011, 11,954 .

48. King, R. C. Y.; Roussel, F.; Brun, J. F.; Gors, C.; Synth. Met. 2012, 162, 1348.

49. Ansari, M. O.; Khan, M. M.; Ansari, S. A.; Lee, J.; Cho, M. H.; RSC Adv. 2014, 4, 23713.

50. Bu, Y.; Chen, Z.; ACS Appl. Mater. Interfaces 2014, 6, 17589.

51. Kohlman, R. S.; Tanner, D. B.; Ihas, G. G.; Synth. Met. 1997, 84, 709.

52. Li, H.; Zhou, J.; Lu, X.; Wang, J.; Qu, S.; Weng, J.; Feng, B.; J. Mater. Sci. Mater. Electron. 2015, 26, 7723.

53. Moliton, A.; Hiorns, R. C.; Polym. Int. 2004, 53, 1397.

54. Zhang, H.; Zong, R.; Zhu, Y.; J. Phys. Chem. C 2009, 113, 4605.

55. Zhang, X.; Wu, J.; Meng, G.; Guo, X.; Liu, C.; Liu, Z.; Appl. Surf. Sci. 2016, 366, 486.

56. Gülce, H.; Eskizeybek, V.; Haspulat, B.; Sari, F.; Gülce, A.; Avci, A.; Ind. Eng. Chem. Res. 2013, 52, 10924.

57. Li, C.; Wang, J.; Guo, H.; Ding, S.; J. Colloid Interface Sci. 2015, 458, 1.

58. Wang, Q.; Hui, J.; Li, J.; Cai, Y.; Yin, S.; Wang, F.; Su, B.; Appl. Surf. Sci. 2013, 283, 577.

59. Nabid, M. R.; Sedghi, R.; Gholami, S.; Oskooie, H. A.; Heravi, M. M.; Photochem. Photobiol. 2013, 89, 24. 
60. Salem, M. A.; Al-Ghonemiy, A. F.; Zaki, A. B.; Appl. Catal., B 2009, $91,59$.

61. Li, Y.; Yu, Y.; Wu, L.; Zhi, J.; Appl. Surf. Sci. 2013, 273, 135.

62. Wang, W.; Xu, J.; Zhang, L.; Sun, S.; Catal. Today 2014, 224, 147.

63. Sharma, S.; Singh, S.; Khare, N.; Colloid Polym. Sci. 2016, $294,917$.

64. Mohamed, R. M.; Aazam, E. S.; Appl. Catal., A 2014, 480, 100.

65. Rasoulifard, M. H.; Seyed Dorraji, M. S.; Amani-Ghadim, A. R.; Keshavarz-Babaeinezhad, N.; Appl. Catal., A 2016, 514, 60.

66. Ansari, M. O.; Khan, M. M.; Ansari, S. A.; Cho, M. H.; New J. Chem. 2015, 39, 8381.

67. Li, C.; Wang, J.; Guo, H.; Ding, S.; J. Colloid Interface Sci. 2015, 458, 1.

68. Neelgund, G. M.; Bliznyuk, V. N.; Oki, A.; Appl. Catal., B 2016, 187, 357.

69. Yang, C.; Liang, A.; Zongshan, Z.; Guanghui, W.; J. Wuhan Univ. Technol. Mater. Sci. Ed. 2014, 29, 468.

70. Mahanta, D.; Manna, U.; Madras, G.; Patil, S.; Appl. Mater. Interfaces 2011, 3, 84 .

71. Sabbaghi, S.; Mohammadi, M.; Ebadi, H.; J. Environ. Eng. 2016, 142, 1.

72. Wei, J.; Zhang, Q.; Liu, Y.; Xiong, R.; Pan, C.; Shi, J.; J. Nanopart. Res. 2011, 13, 3157 .

73. Leng, C.; Wei, J.; Liu, Z.; Xiong, R.; Pan, C.; Shi, J.; J. Nanopart. Res. 2013, 15:1643, 1 .

74. Li, Q.; Zhang, C.; Li, J.; Appl. Surf. Sci. 2010, 257, 944.

75. Ansari, M. O.; Khan, M. M.; Ansari, S. A.; Raju, K.; Lee, J.; Cho, M. H.; Appl. Mater. Interfaces 2014, 6, 8124.

76. Zhang, H.; Zhu, Y.; J. Phys. Chem. C 2010, 114, 5822.

77. Lin, L.; Wu, Q.; Polym. Polym. Compos. 2012, 20, 367.

78. Deng, Y.; Tang, L.; Zeng, G.; Dong, H.; Yan, M.; Wang, J.; Hu, W.; Wang, J.; Zhou, Y.; Tang, J.; Appl. Surf. Sci. 2016, 387, 882.

79. Xiong, P.; Chen, Q.; He, M.; Sun, X.; Wang, X.; J. Mater. Chem. 2012, $22,17485$.

80. Li, W.; Tian, Y.; Zhao, C.; Zhang, Q.; Geng, W.; Chem. Eng. J. 2016, $303,282$.

81. Chen, X.; Li, H.; Wu, H.; Wu, Y.; Shang, Y.; Pan, J.; Xiong, X.; Mater. Lett. 2016, 172, 52.

82. Ziolli, R. L.; Jardim, W. F.; Quim. Nova 1998, 21, 319.

83. Ameen, S.; Seo, H. K.; Shaheer Akhtar, M.; Shin, H. S.; Chem. Eng. J. 2012, 210, 220.

84. Zhang, J.; Bi, H.; He, G.; Zhou, Y.; Chen, H.; J. Environ. Chem. Eng. $\mathbf{2 0 1 4}, 2,952$.

85. Miao, J.; Xie, A.; Li, S.; Huang, F.; Cao, J.; Shen, Y.; Appl. Surf. Sci. 2016, 360, 594.

86. Gemeay, A. H.; El-Sharkawy, R. G.; Mansour, I. A.; Zaki, A. B.; Appl. Catal., B 2008, 80, 106.

87. Ghavami, M.; Kassaee, M. Z.; Mohammadi, R.; Koohi, M.; Haerizadeh, B. N.; P; Solid State Sci. 2014, 38, 143.

88. Huang, X.; Wang, G.; Yang, M.; Guo, W.; Gao, H.; Mater. Lett. 2011, $65,2887$.
89. Liu, Z.; Miao, Y.-E.; Liu, M.; Ding, Q.; Tjiu, W. W.; Cui, X.; Liu, T.; J. Colloid Interface Sci. 2014, 424, 49.

90. Su, H.; Wang, T.; Zhang, S.; Song, J.; Mao, C.; Niu, H.; Jin, B.; Wu, J.; Tian, Y.; Solid State Sci. 2012, 14, 677.

91. Özbay, B.; Genç, N.; Özbay, İ.; Bağhaki, B.; Zor, S.; Clean Technol. Environ. Policy 2016, 18, 2591.

92. Li, C.; Zhou, T.; Zhu, T.; Li, X; RSC Adv. 2015, 5, 98482.

93. Yang, S.-B. ; Jo, W.-K., Cho, S.-B.; Yu, M.-S.; Asian J. Chem. 2015, 27, 4179.

94. Subramanian, E.; Subbulakshmi, S.; Murugan, C.; Mater. Res. Bull. 2014, 51, 128.

95. Ramli, C. A. Z.; Asim, N.; Isahak, W. N. R. W.; Emdadi, Z.; Ahmadludin, N.; Yarmo, M. A.; Sopian, K.; Sci. World J. 2014, 2014, 1.

96. Cheng, Y.; An, L.; Gao, F.; Wang, G.; Li, X.; Chen, X.; Res. Chem. Intermed. 2013, 39, 3969.

97. Jo, W.-K.; Kang, H.; Mater. Chem. Phys. 2013, 143, 247.

98. Ahmad, R.; Mondal, P. K.; J. Dispersion Sci. Technol. 2012, 33, 380.

99. Liao, G.; Chen, S.; Quan, X.; Zhang, Y.; Zhao, H.; Appl. Catal., B 2011, $102,126$.

100. Wang, Y.; Xu, J.; Zong, W.; Zhu, Y.; J. Solid State Chem. 2011, 184, 1433.

101. Sarmah, S.; Kumar, A.; Indian J. Phys 2011, 85, 713.

102. Min, S.; Wang, F.; Han, Y.; J. Mater. Sci. 2007, 42, 9966.

103. Wang, X.; Chen, G.; Zhang, J.; Catal. Commun. 2013, 31, 57.

104. Kannusamy, P.; Sivalingam, T.; Colloids Surf., B 2013, 108, 229.

105. Huang, X.; Wang, G.; Yang, M.; Guo, W.; Gao, H.; Mater. Lett. 2011, 65, 2887.

106. Ma, H.; Li, C.; Yin, J.; Pu, X.; Zhang, D.; Su, C.; Wang, X.; Shao, X.; Mater. Lett. 2016, 168,

107. Wu, W.; Liang, S.; Shen, L.; Ding, Z.; Zheng, H.; Su, W.; Wu, L.; J. Alloys Compd. 2012, 520,

108. Kant, S.; Kalia, S.; Kumar, A.; J. Alloys Compd. 2013, 578, 249.

109. Sharma, G.; Naushad, M.; Kumar, A.; Devi, S.; Khan, M. R.; Iran. Polym. J. 2015, 24, 1003.

110. Kim, K. N.; Jung, H.-R.; Lee, W.-J.; J. Photochem. Photobiol., A 2016, $321,257$.

111. Li, X.; Teng, W.; Zhao, Q.; Wang, L.; J. Nanopart. Res. 2011, 13, 6813.

112. Xu, H.; Zhang, J.; Chen, Y.; Lu, H.; Zhuang, J.; Li, J.; Mater. Lett. 2014, $117,21$.

113. Malinauskas, A.; J. Power Sources 2004, 126, 214

114. Eskizeybek, V.; Sari, F.; Gülce, H.; Gülce, A.; Avci, A.; Appl. Catal., B. 2012, 119-120, 197.

115. Yang, Y.; Luan, J.; Molecules 2012, 17, 2752.

116. Ahmed, S.; Rasul, M. G.; Brown, R.; Hashib, M. A.; J. Environ. Manage. 2011, 92, 311 .

117. Baguckis, A.; Novickovas, A.; Mekys, A.; Tamošiunas, V.; J. Photonics Energy 2016, 6, 35501.

118. Malato, S.; Maldonado, M. I.; Fernández-Ibáñez, P.; Oller, I.; Polo, I.; Sánchez-Moreno, R.; Mater. Sci. Semicond. Process. 2016, 42, 15. 